\title{
Enantioselective synthesis of (-)-Pentalenene
}

Mahesh K. Pallerla and Joseph M. Fox

Brown Laboratories, Department of Chemistry and Biochemistry, University of Delaware, Newark DE 19716

Spectral Supporting Information 
${ }^{1} \mathrm{H}$ NMR spectrum of $\mathbf{3}\left(400 \mathrm{MHz}, \mathrm{CDCl}_{3}\right)$

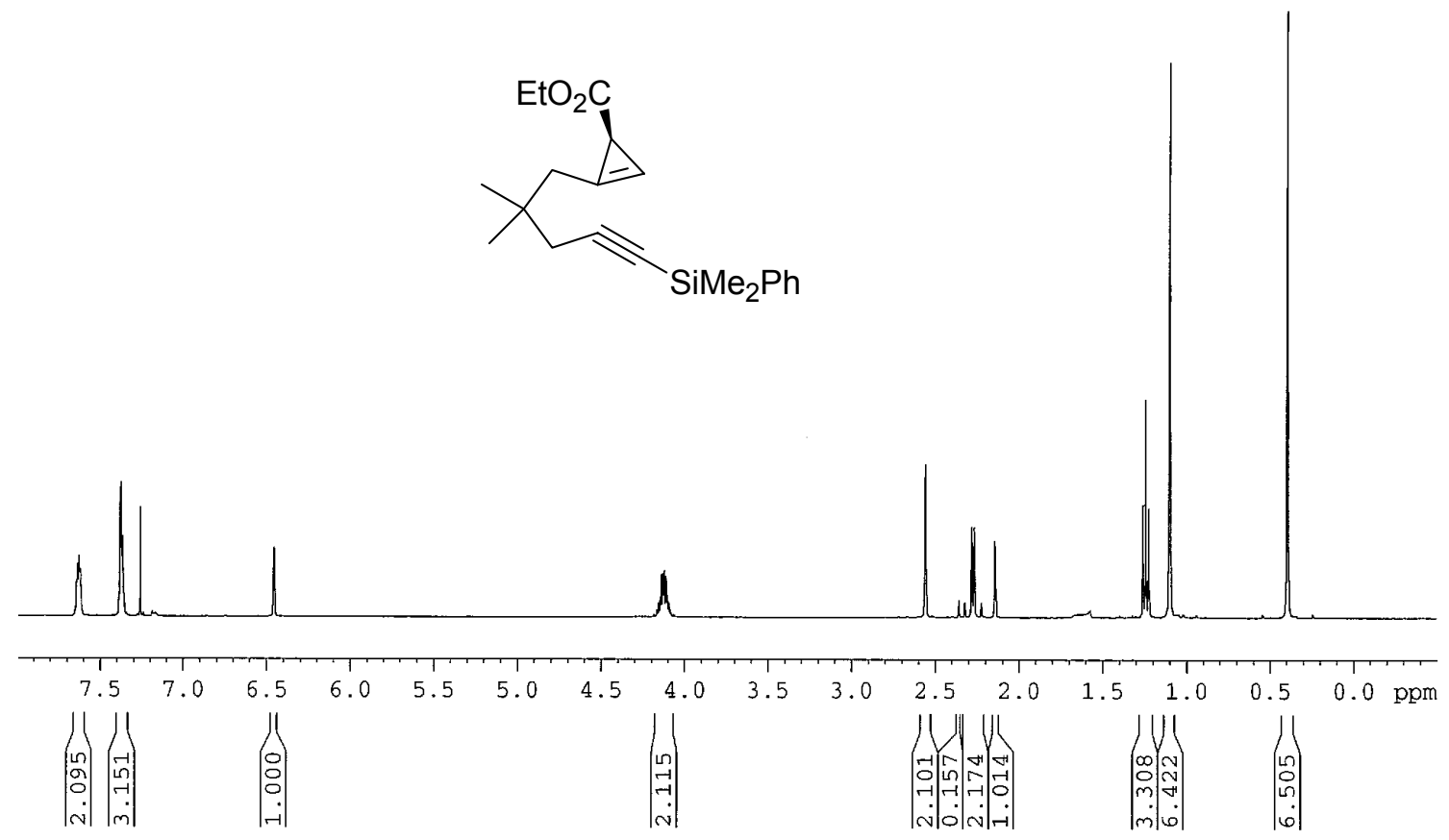

${ }^{13} \mathrm{C}$ APT NMR spectrum of $16\left(100 \mathrm{MHz}, \mathrm{CDCl}_{3}\right)$
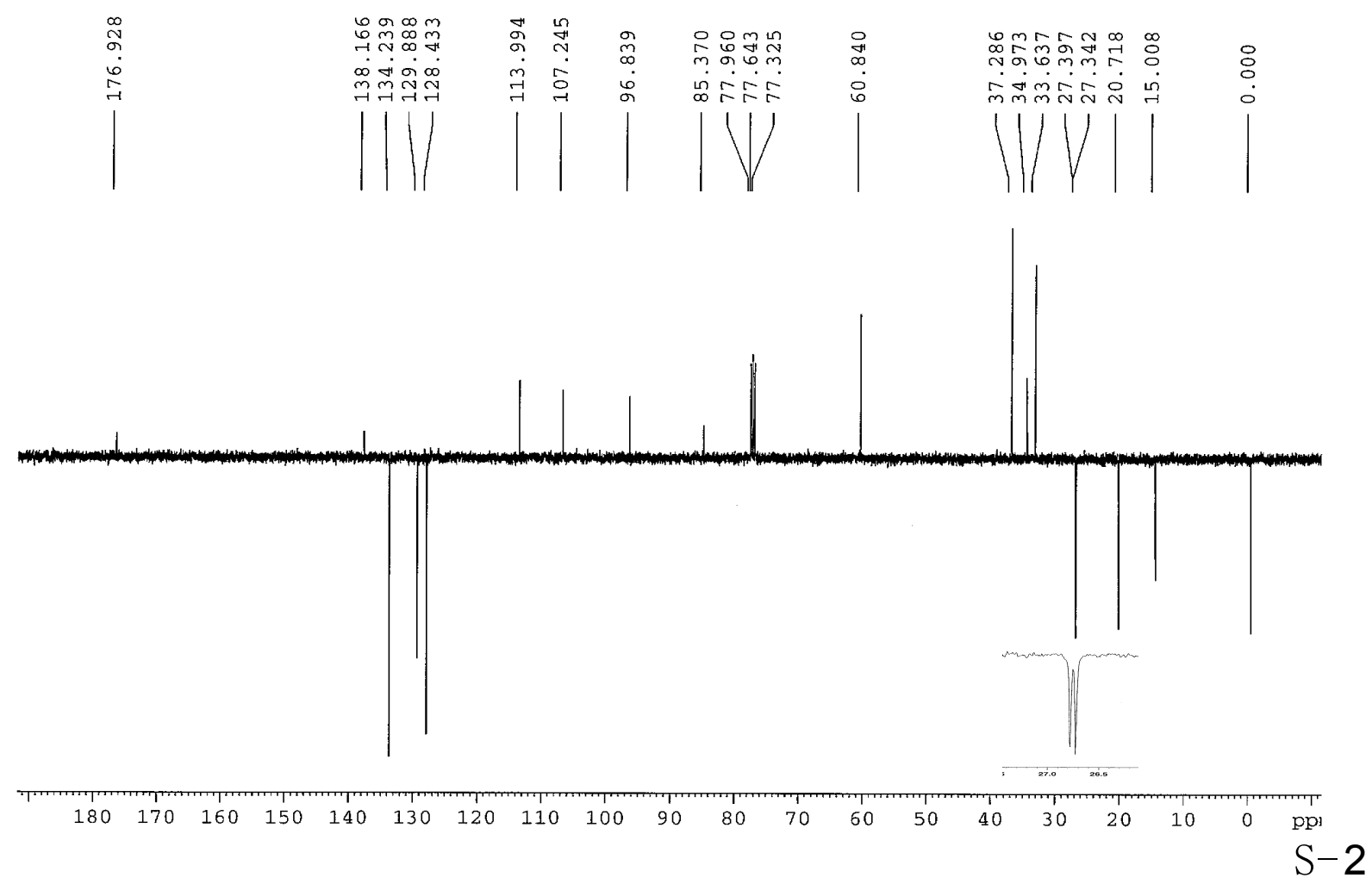
Enantiomeric Excess of IV-3 using $(R, R)-\mathrm{Rh}_{2}(\mathrm{OAc})(\mathrm{DPTI})_{3}$ :
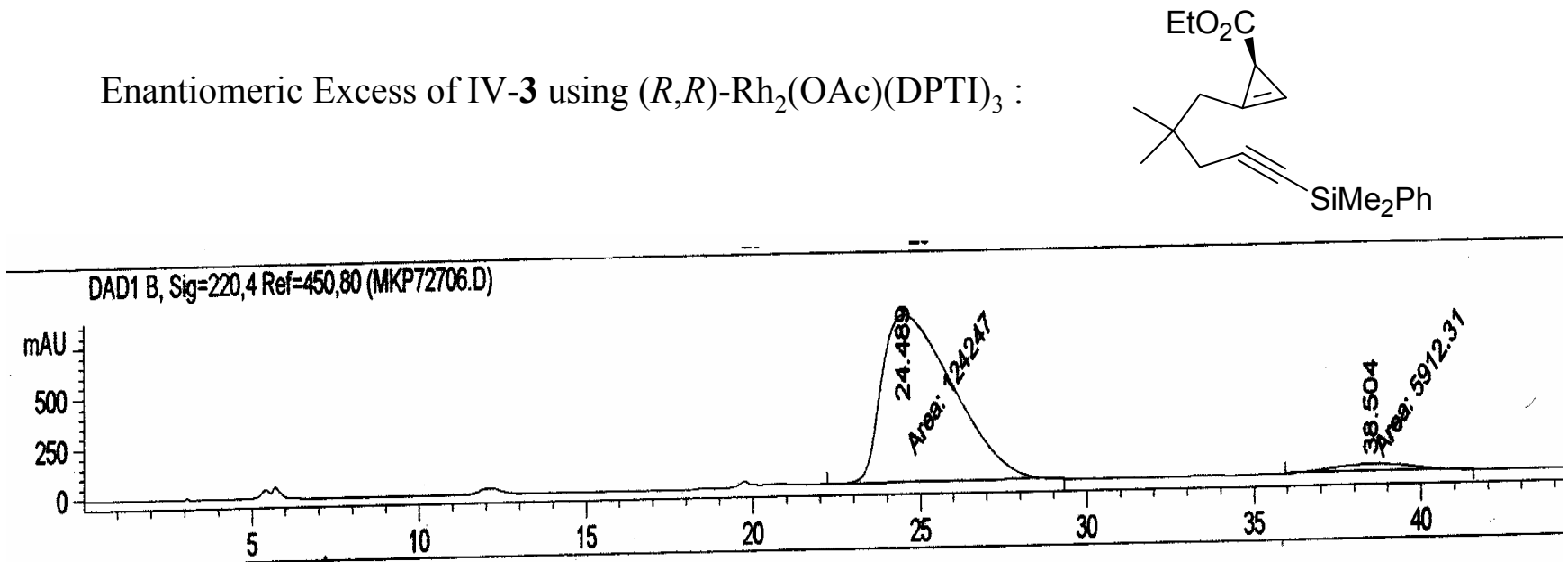

Signal 2: DAD1 B, Sig=220,4 $\operatorname{Ref}=450,80$

\begin{tabular}{|c|c|c|c|c|c|c|}
\hline $\begin{array}{c}\text { Peak } \\
\text { \# }\end{array}$ & $\begin{array}{l}\text { RetTime } \\
\text { [min] }\end{array}$ & Type & $\begin{array}{l}\text { Width } \\
\text { [min] }\end{array}$ & $\begin{array}{c}\text { Area } \\
{\left[\mathrm{mAU}{ }^{\star} \mathrm{s}\right]}\end{array}$ & $\begin{array}{l}\text { Height } \\
\text { [mAU] }\end{array}$ & $\begin{array}{c}\text { Area } \\
\frac{\circ}{6}\end{array}$ \\
\hline 1 & 24.489 & MM & 2.4929 & $1.24247 e^{5}$ & 830.67151 & 576 \\
\hline$\frac{1}{2}$ & 38.504 & $\mathrm{MM}$ & 2.7917 & 5912.30518 & 35.29733 & 4.5424 \\
\hline
\end{tabular}

Totals :

$1.30159 \mathrm{e} 5 \quad 865.96884$.

Racemic IV-3 using $\mathrm{Rh}_{2}(\mathrm{OAc})_{4}$ :

DAD1 A, Sig $=220,4$ Ref $=450,80$ (MKPNRAC2.D)

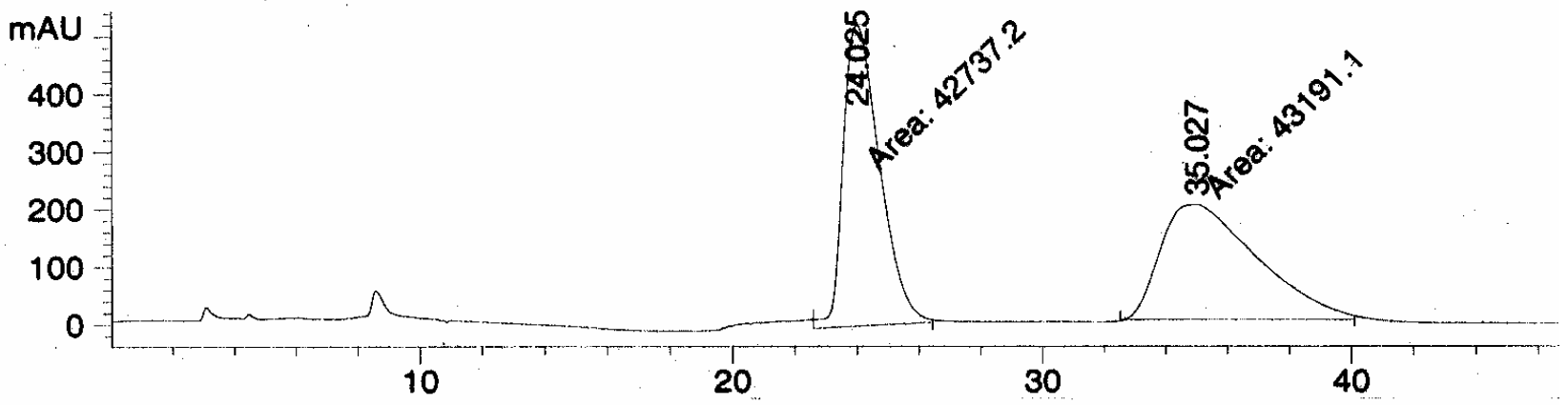

Signal 1: DAD1 A, Sig $=220,4$ Ref $=450,80$

\begin{tabular}{|c|c|c|c|c|c|c|}
\hline $\begin{array}{c}\text { Peak } \\
\#\end{array}$ & $\begin{array}{l}\text { RetTime } \\
\text { [min] }\end{array}$ & Type & $\begin{array}{l}\text { Width } \\
\text { [min] }\end{array}$ & $\begin{array}{c}\text { Area } \\
{\left[\mathrm{mAU}{ }^{*} \mathrm{~s}\right]}\end{array}$ & $\begin{array}{l}\text { Height } \\
{[\mathrm{mAU}]}\end{array}$ & $\begin{array}{c}\text { Area } \\
8\end{array}$ \\
\hline$\frac{1}{2}$ & $\begin{array}{l}24.025 \\
35.027\end{array}$ & $\begin{array}{l}\text { MM } \\
\text { MM }\end{array}$ & $\begin{array}{r}1.3623 \\
3.6078\end{array}$ & $\begin{array}{l}4.27372 \mathrm{e} 4 \\
4.31911 \mathrm{e} 4\end{array}$ & $\begin{array}{l}522.86456 \\
199.52675\end{array}$ & $\begin{array}{l}49.7359 \\
50.2641\end{array}$ \\
\hline & & & & $8.59282 \mathrm{e} 4$ & 722.39131 & \\
\hline
\end{tabular}


Enantiomeric Excess of IV-3 using $\mathrm{Rh}_{2}(R \text {-MEPY })_{4}$ at $25^{\circ} \mathrm{C}$ :

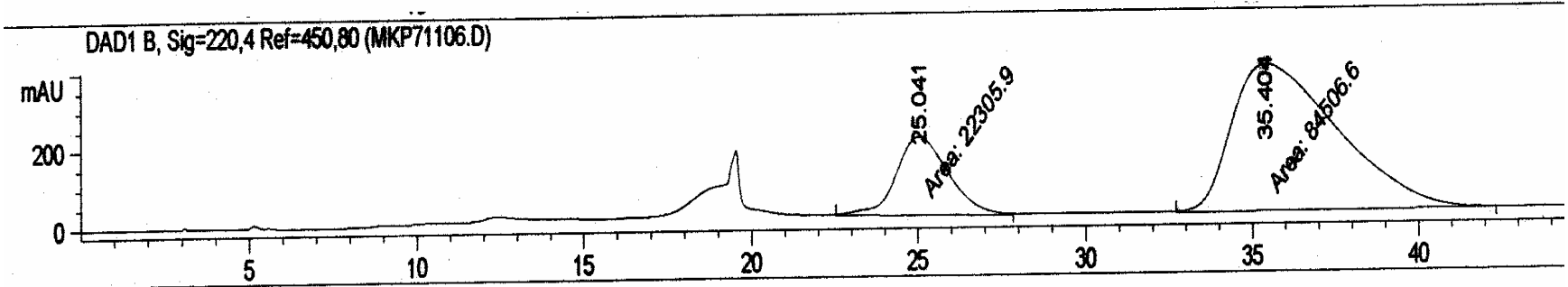

Signal 2: DAD1 B, Sig=220,4 Ref $=450,80$

\begin{tabular}{|c|c|c|c|c|c|c|}
\hline Peak & $\begin{array}{l}\text { RetTime } \\
\text { [min] }\end{array}$ & Type & $\begin{array}{l}\text { width } \\
\text { [min] }\end{array}$ & $\begin{array}{c}\text { Area } \\
{\left[\mathrm{mAU}^{\star} \mathrm{s}\right]}\end{array}$ & $\begin{array}{l}\text { Height } \\
\text { [mAU] }\end{array}$ & $\begin{array}{c}\text { Area } \\
\frac{8}{8}\end{array}$ \\
\hline $\begin{array}{l}1 \\
2\end{array}$ & $\begin{array}{l}25.041 \\
35.404\end{array}$ & $\begin{array}{l}\text { MM } \\
\text { MM }\end{array}$ & $\begin{array}{l}1.8262 \\
3.7031\end{array}$ & $\begin{array}{l}2.23059 \mathrm{e} 4 \\
8.45066 \mathrm{e}\end{array}$ & $\begin{array}{l}203.57597 \\
380.34302\end{array}$ & $\begin{array}{l}20.8832 \\
79.1168\end{array}$ \\
\hline a & : & & & $1.06812 \mathrm{e} 5$ & 583.91899 & \\
\hline
\end{tabular}

Enantiomeric Excess of IV-3 using $\mathrm{Rh}_{2}(R \text {-MEPY })_{4}$ at $0{ }^{\circ} \mathrm{C}$ :

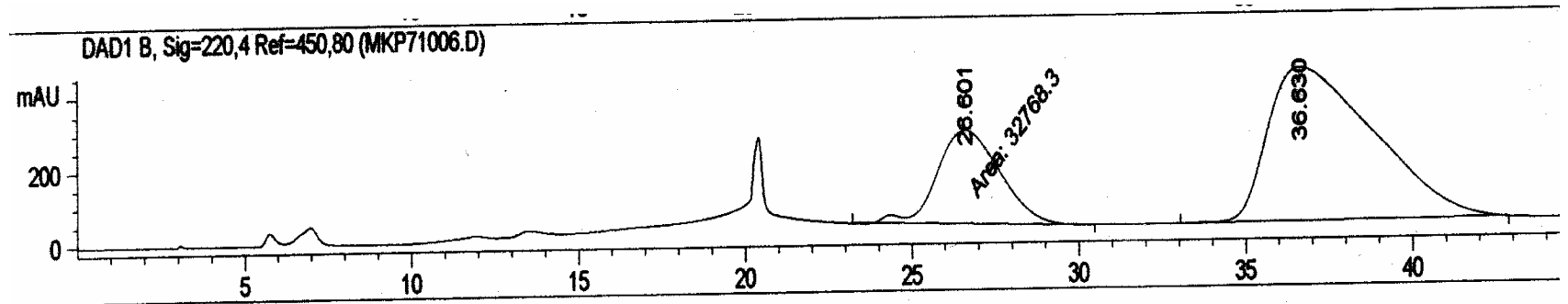

Signal 2: DAD1 B, Sig $=220,4$ Ref $=450,80$

\begin{tabular}{|c|c|c|c|c|c|c|}
\hline $\begin{array}{c}\text { Peak } \\
\quad \#\end{array}$ & $\begin{array}{l}\text { RetTime } \\
\text { [min] }\end{array}$ & Type & $\begin{array}{c}\text { Width } \\
\text { [min] }\end{array}$ & $\begin{array}{c}\text { Area } \\
{\left[\mathrm{mAU}^{\star} \mathrm{s}\right]}\end{array}$ & $\begin{array}{l}\text { Height } \\
\text { [mAU] }\end{array}$ & $\begin{array}{c}\text { Area } \\
\frac{\circ}{0}\end{array}$ \\
\hline $\begin{array}{l}1 \\
2\end{array}$ & $\begin{array}{l}26.601 \\
36.630\end{array}$ & $\begin{array}{l}\text { MM } \\
\text { PB }\end{array}$ & $\begin{array}{l}2.1708 \\
2.6150\end{array}$ & $\begin{array}{l}3.27683 e^{4} \\
9.16897 e^{4}\end{array}$ & $\begin{array}{l}251.58812 \\
414.64609\end{array}$ & $\begin{array}{l}26.3288 \\
73.6712\end{array}$ \\
\hline otal & : & & & $1.24458 \mathrm{e} 5$ & 666.23421 & \\
\hline
\end{tabular}


${ }^{1} \mathrm{H}$ NMR spectrum of $7\left(400 \mathrm{MHz}, \mathrm{CDCl}_{3}\right)$

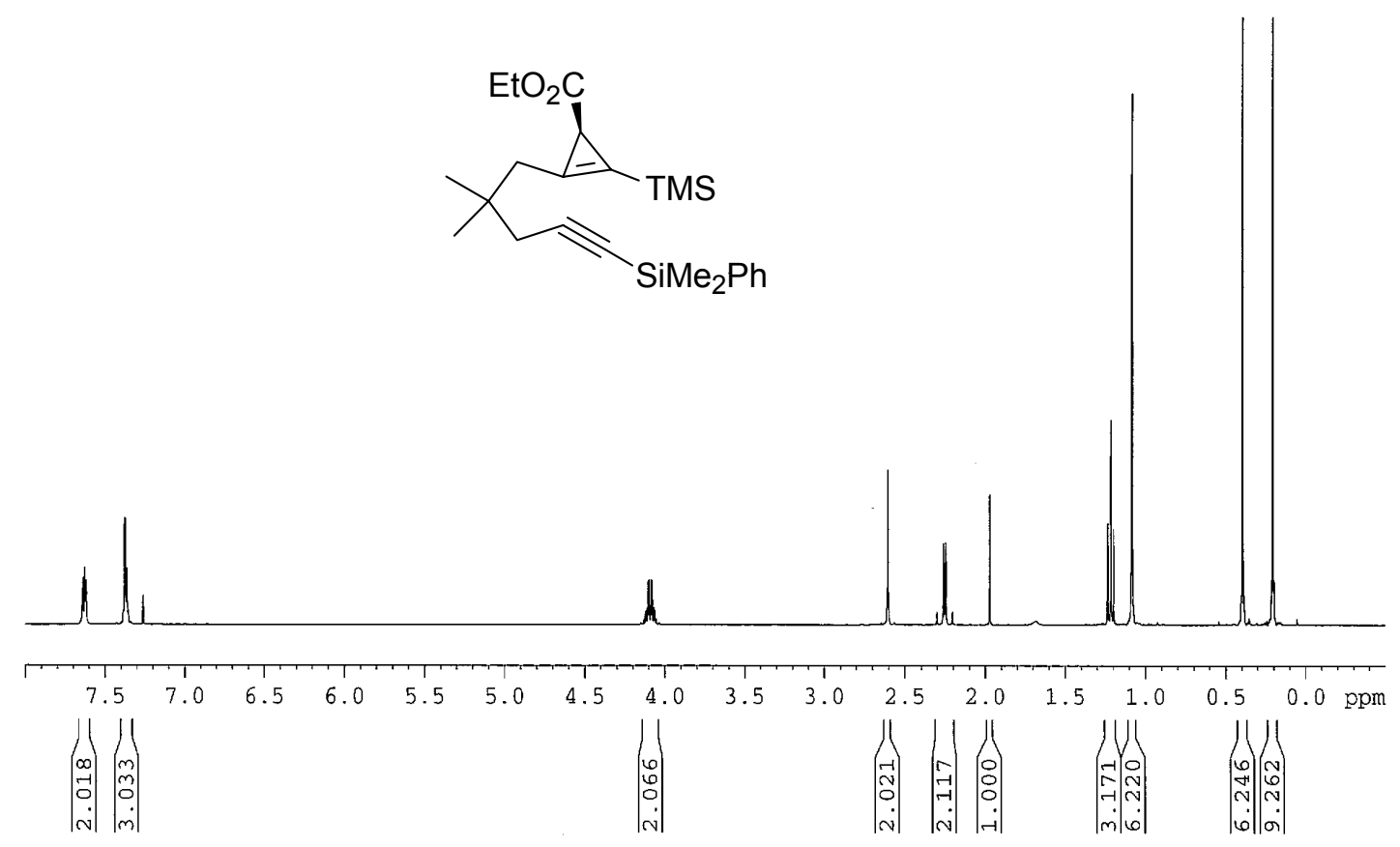

${ }^{13} \mathrm{C}$ APT NMR spectrum of $7\left(100 \mathrm{MHz}, \mathrm{CDCl}_{3}\right)$
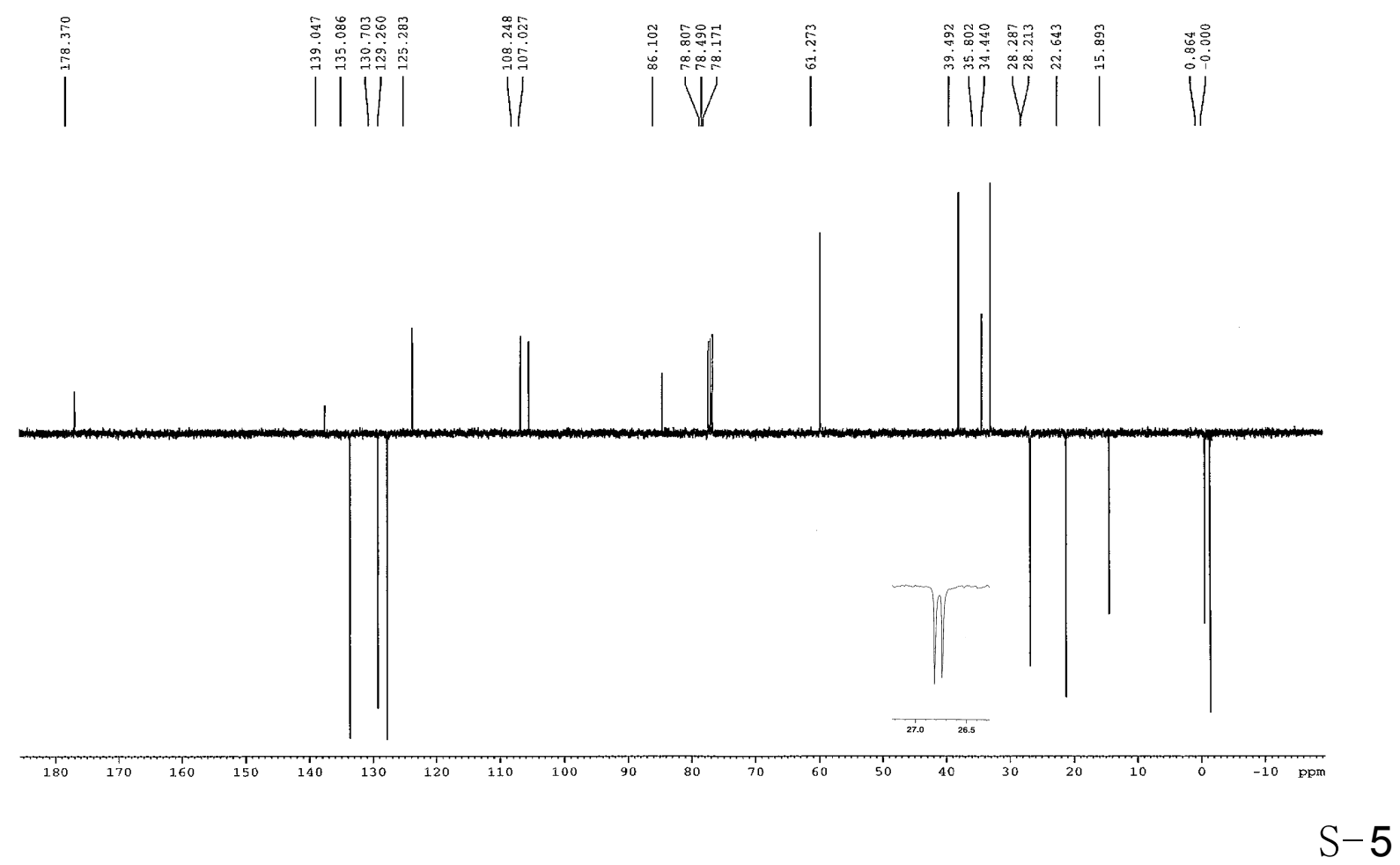
${ }^{1} \mathrm{H}$ NMR spectrum of $8\left(400 \mathrm{MHz}, \mathrm{CDCl}_{3}\right)$ [MAJOR DIASTEREOMER]

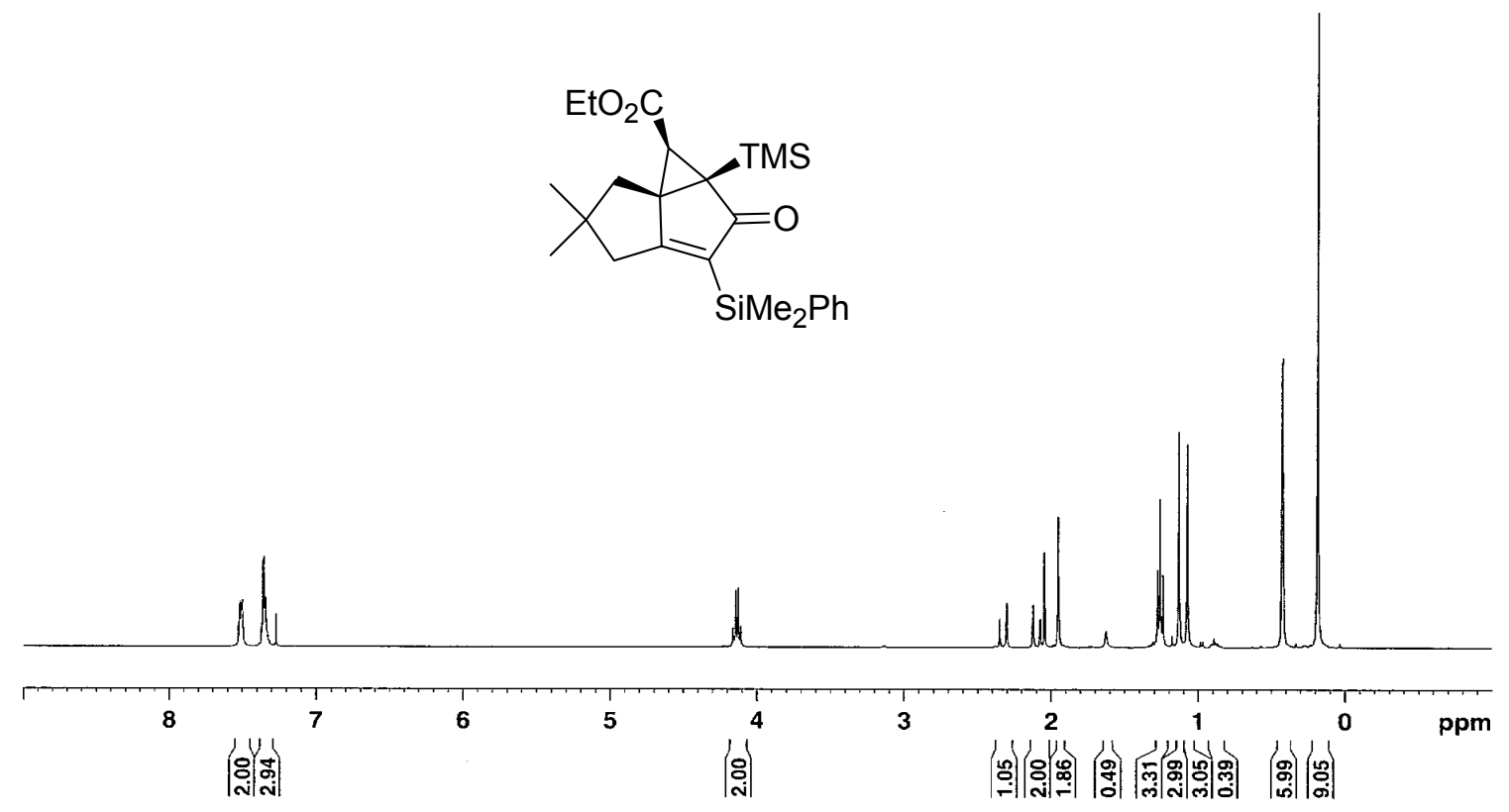

${ }^{13} \mathrm{C}$ APT NMR spectrum of $8\left(100 \mathrm{MHz}, \mathrm{CDCl}_{3}\right)$
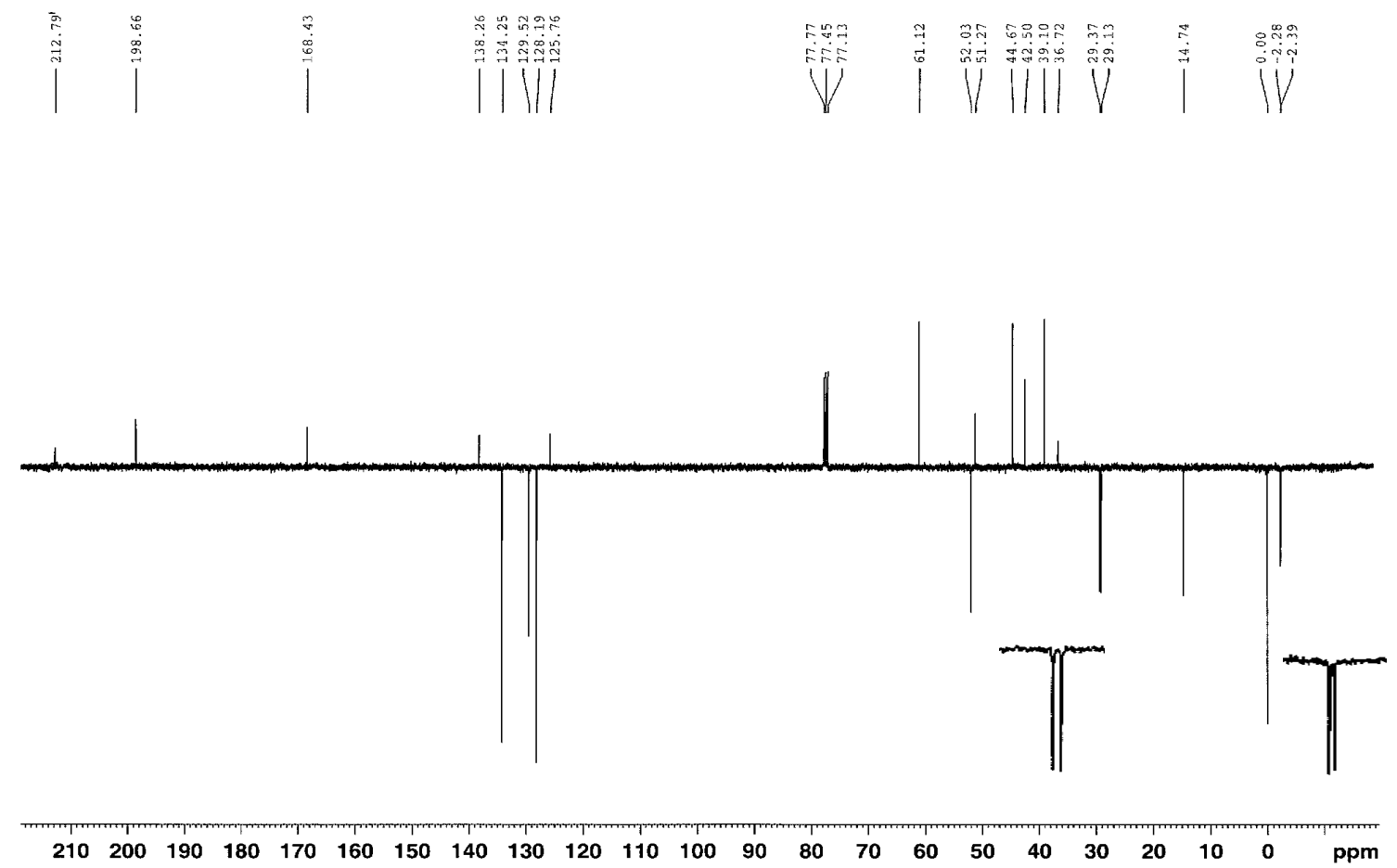
${ }^{1} \mathrm{H}$ NMR spectrum of $9\left(400 \mathrm{MHz}, \mathrm{CDCl}_{3}\right)$ [MINOR DIASTEREOMER]

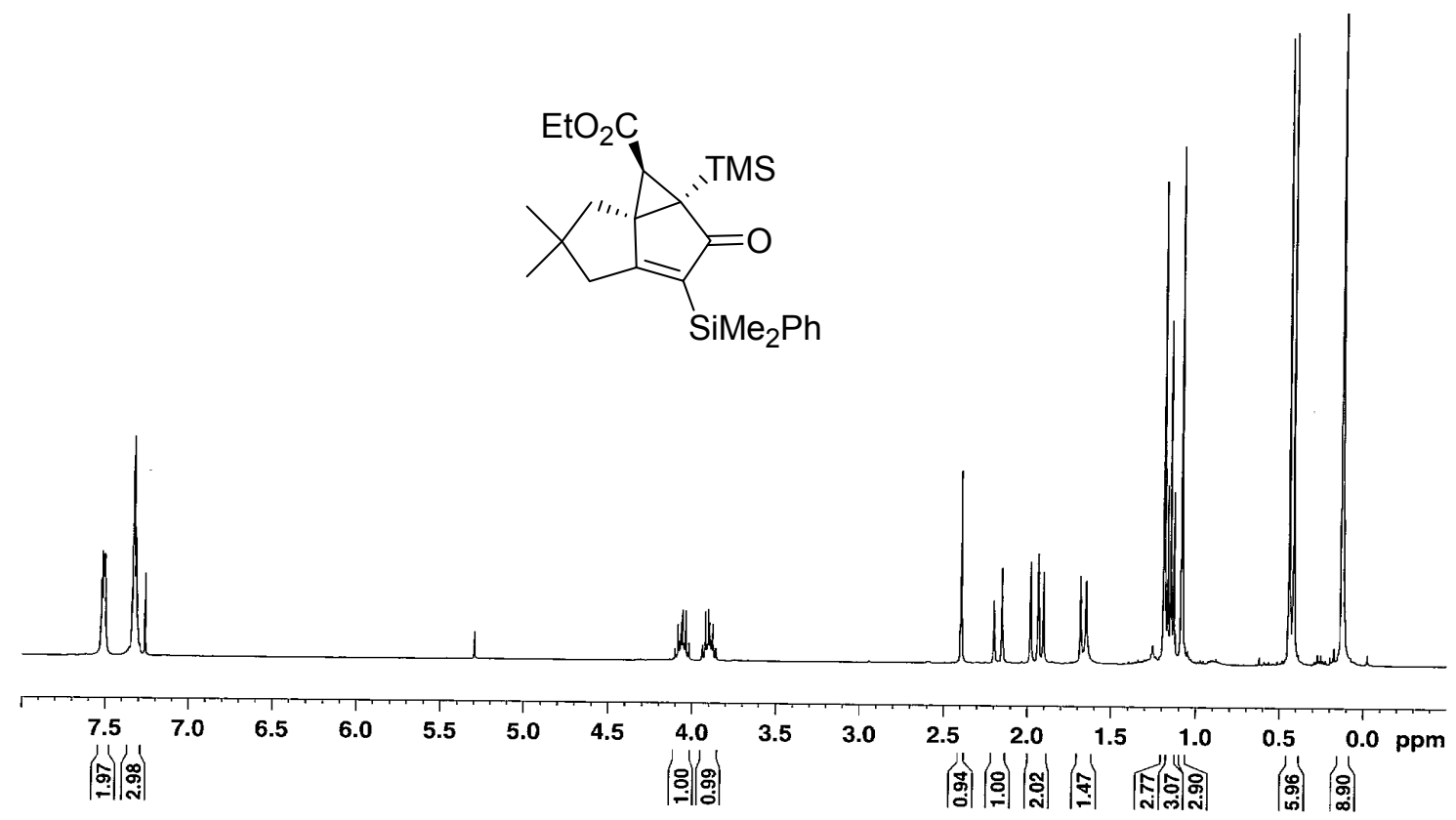

${ }^{13} \mathrm{C}$ APT NMR spectrum of $9\left(100 \mathrm{MHz}, \mathrm{CDCl}_{3}\right)$

-
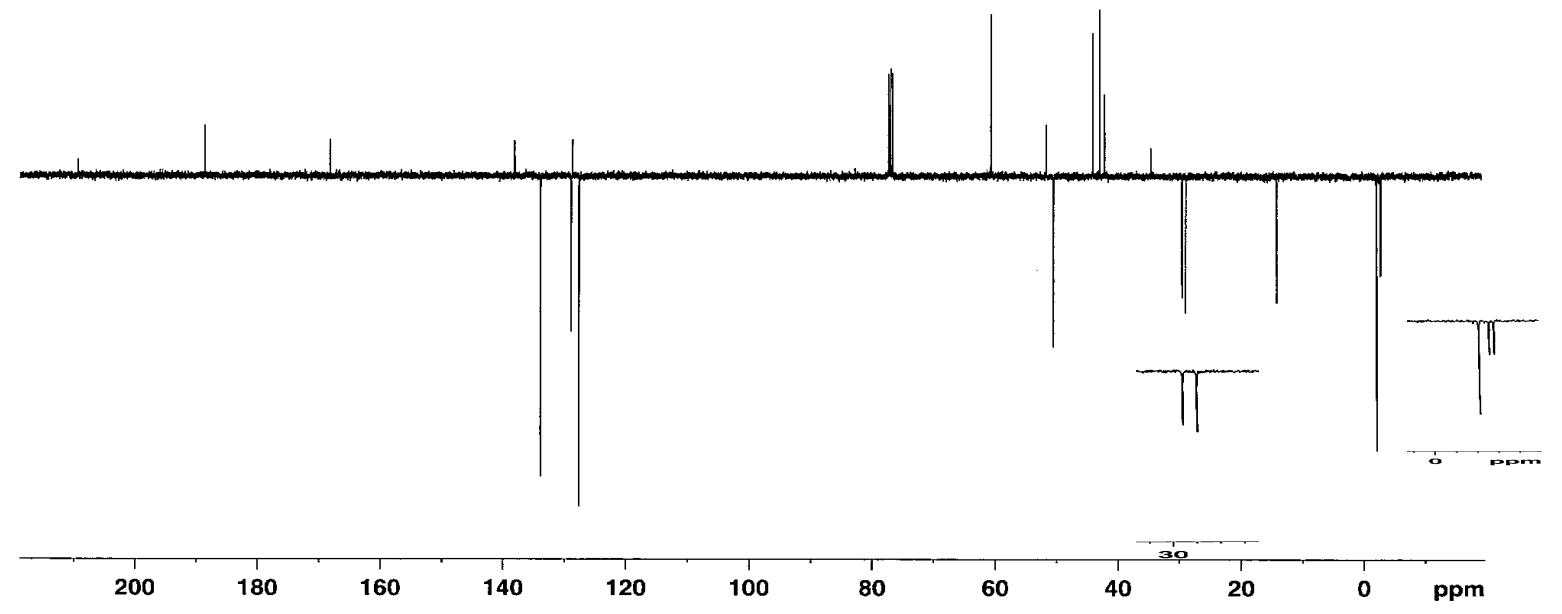
${ }^{1} \mathrm{H}$ NMR spectrum of $\mathbf{2 a}\left(400 \mathrm{MHz}, \mathrm{CDCl}_{3}\right)$. Diastereomer that elutes quickly on $\mathrm{SiO}_{2}$ chromatography.
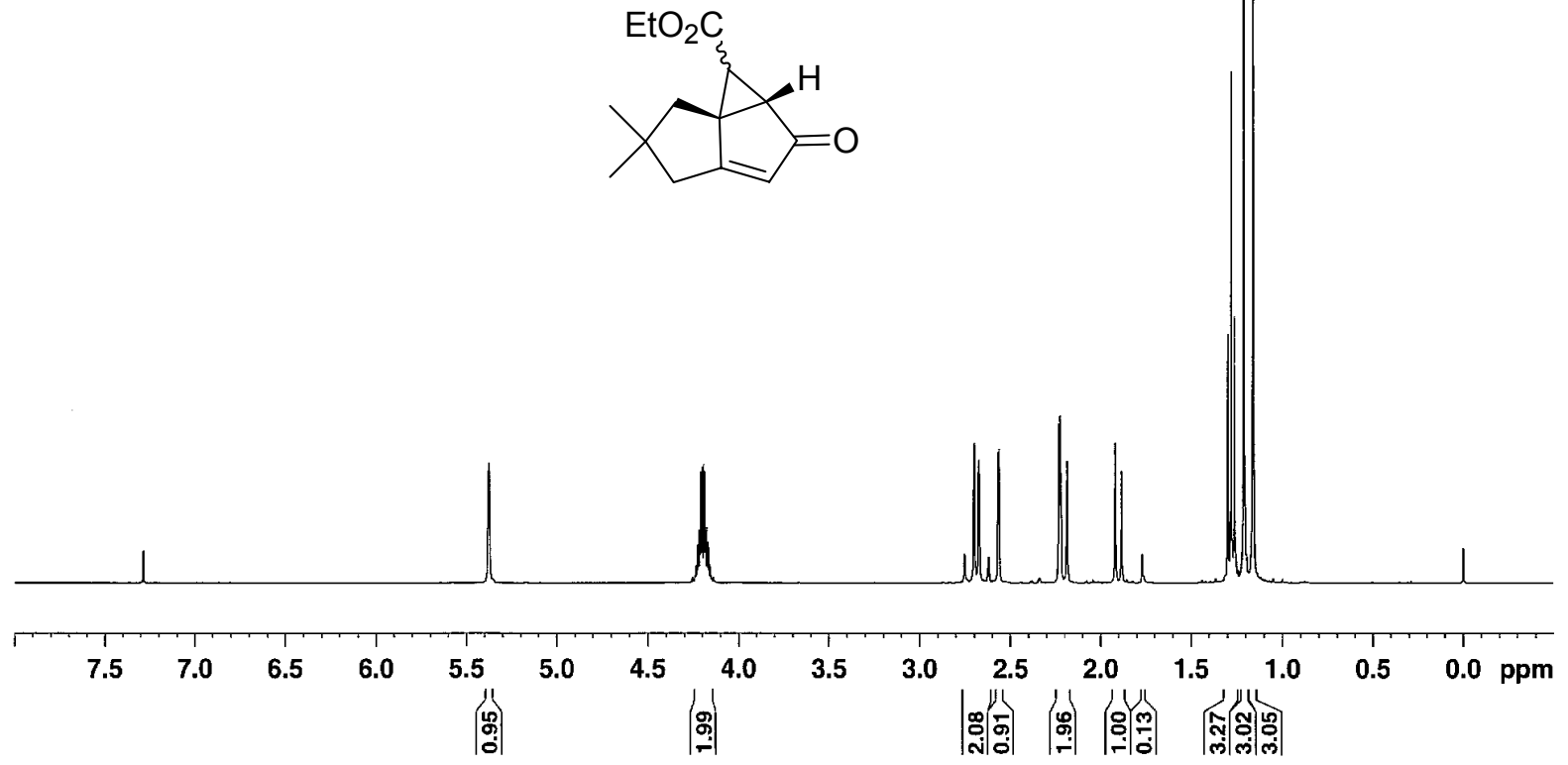

${ }^{13} \mathrm{C}$ APT NMR spectrum of $\mathbf{2 a}\left(100 \mathrm{MHz}, \mathrm{CDCl}_{3}\right)$
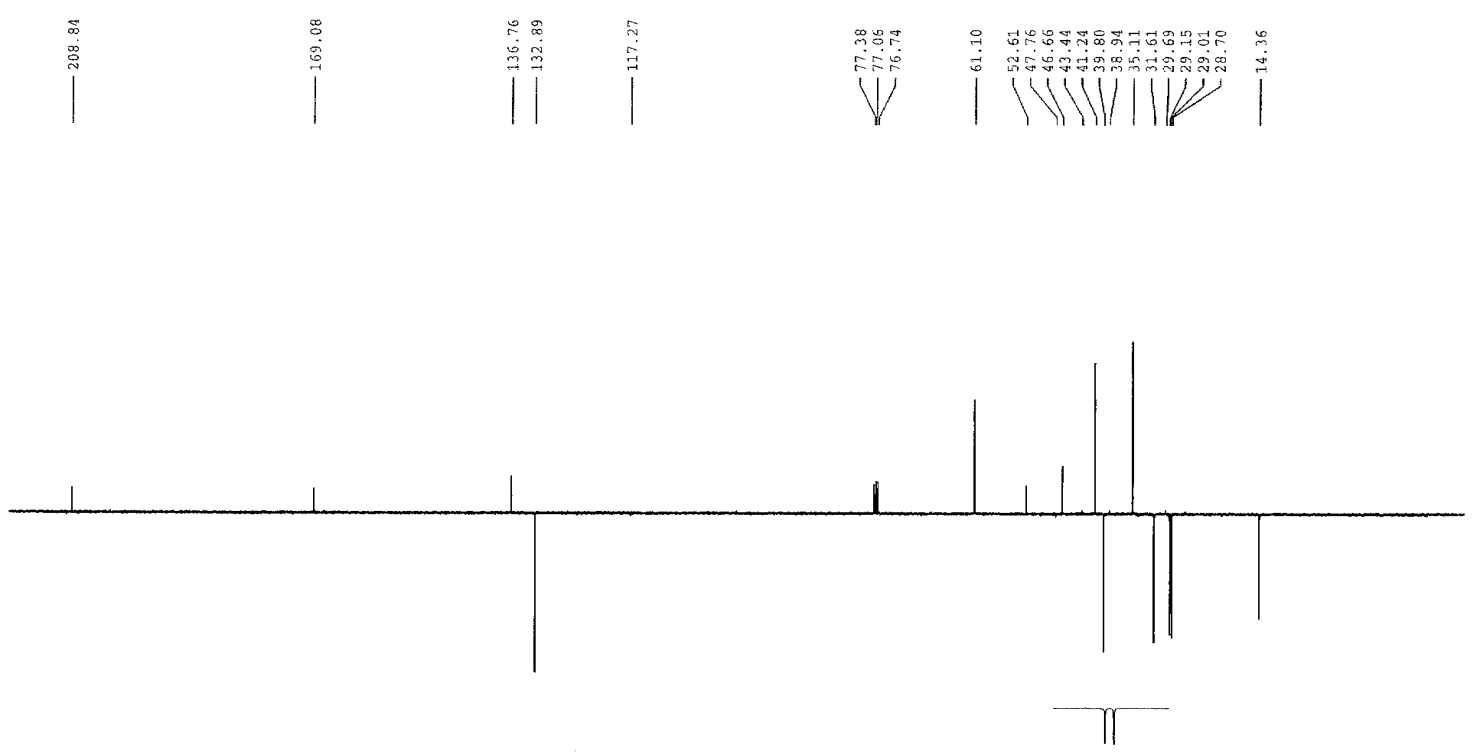

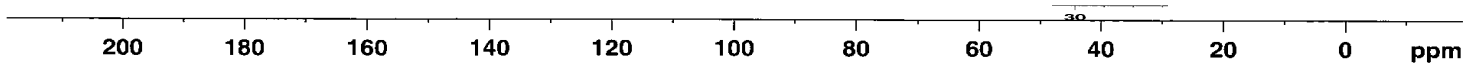


${ }^{1} \mathrm{H}$ NMR spectrum of $\mathbf{2} \mathbf{b}\left(400 \mathrm{MHz}, \mathrm{CDCl}_{3}\right)$. Diastereomer that elutes slowly on $\mathrm{SiO}_{2}$ chromatography.
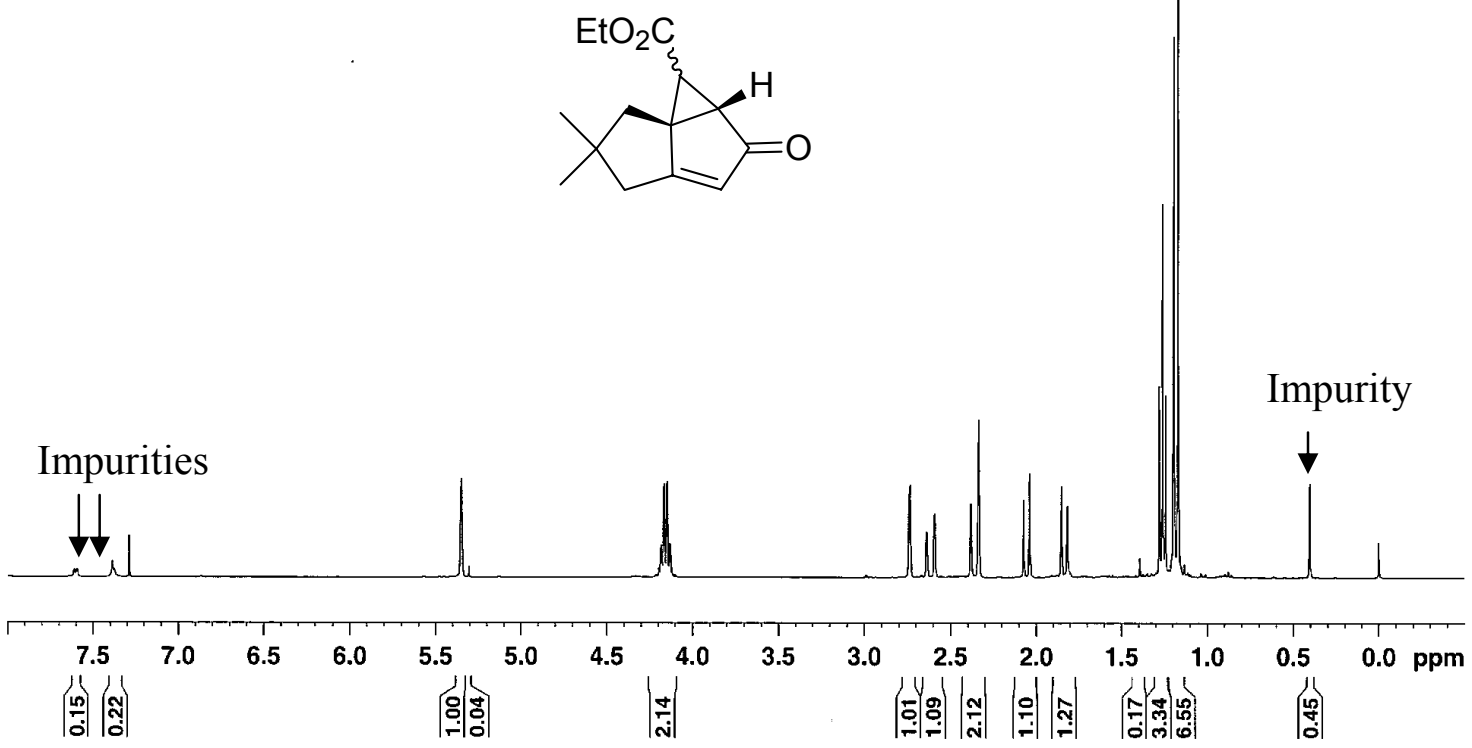

${ }^{13} \mathrm{C}$ APT NMR spectrum of $\mathbf{2 b}\left(100 \mathrm{MHz}, \mathrm{CDCl}_{3}\right)$
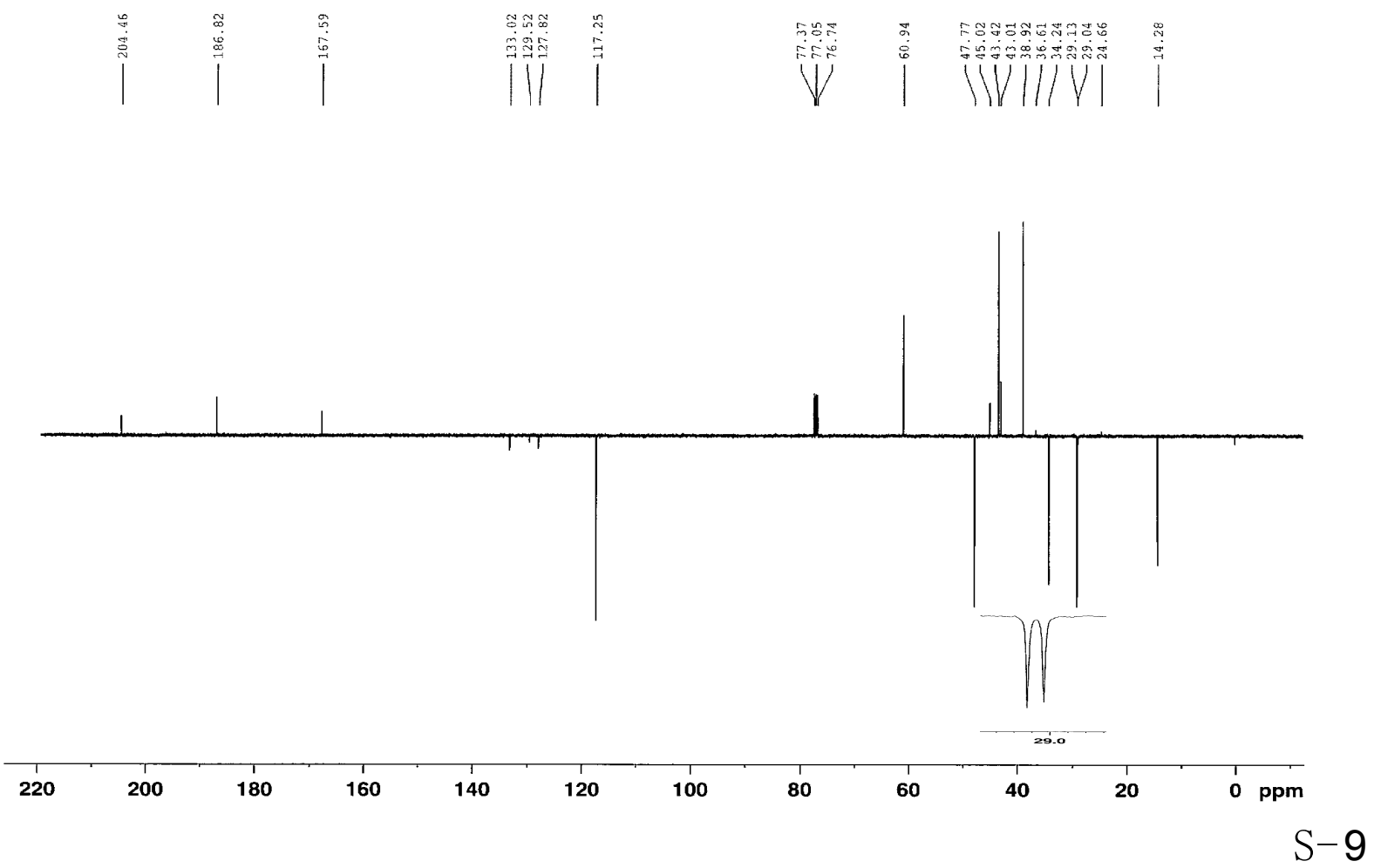
${ }^{1} \mathrm{H}$ NMR spectrum of $\mathbf{1 0}\left(400 \mathrm{MHz}, \mathrm{CDCl}_{3}\right)$

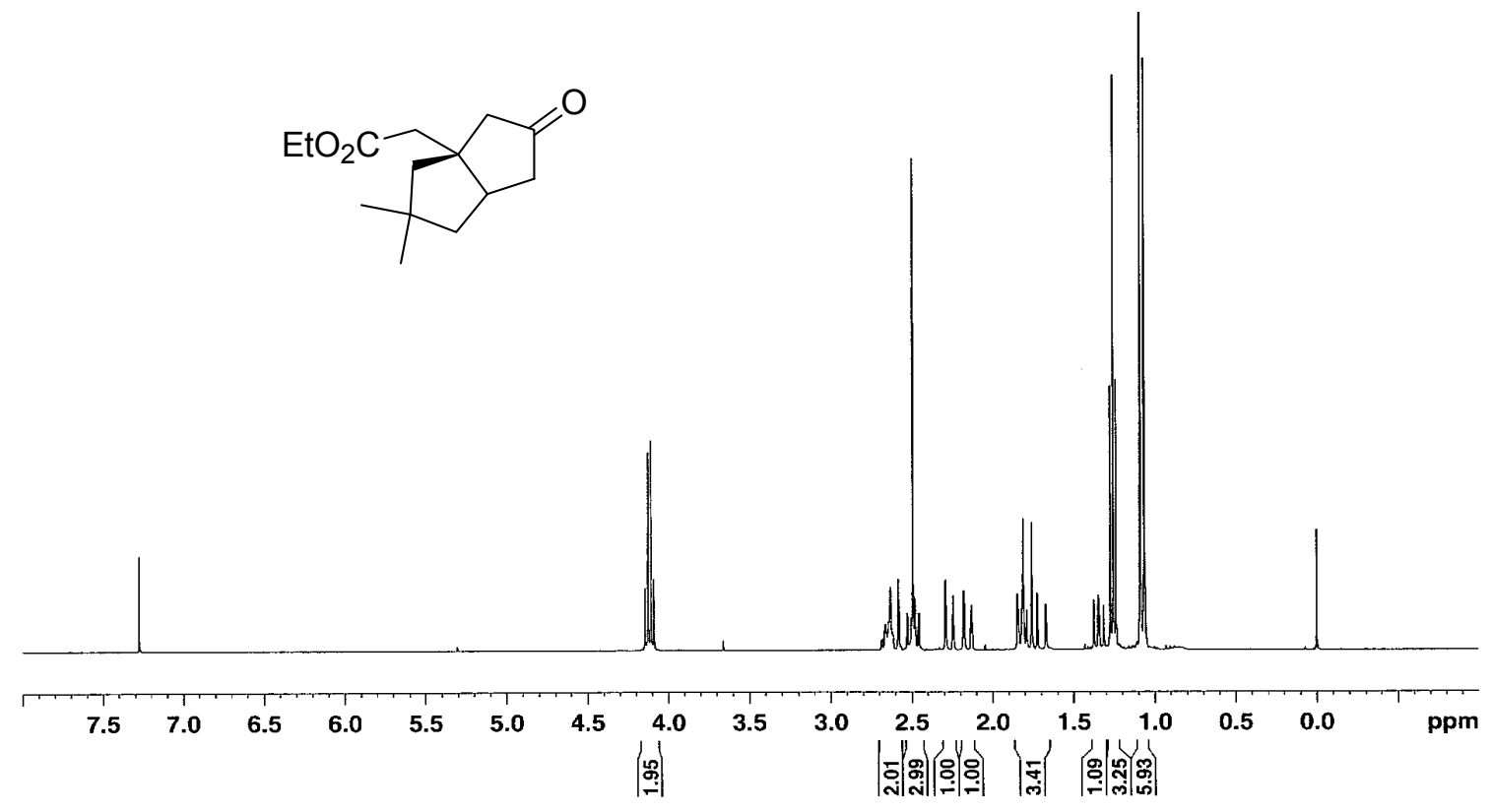

${ }^{13} \mathrm{C}$ APT NMR spectrum of $\mathbf{1 0}\left(100 \mathrm{MHz}, \mathrm{CDCl}_{3}\right)$
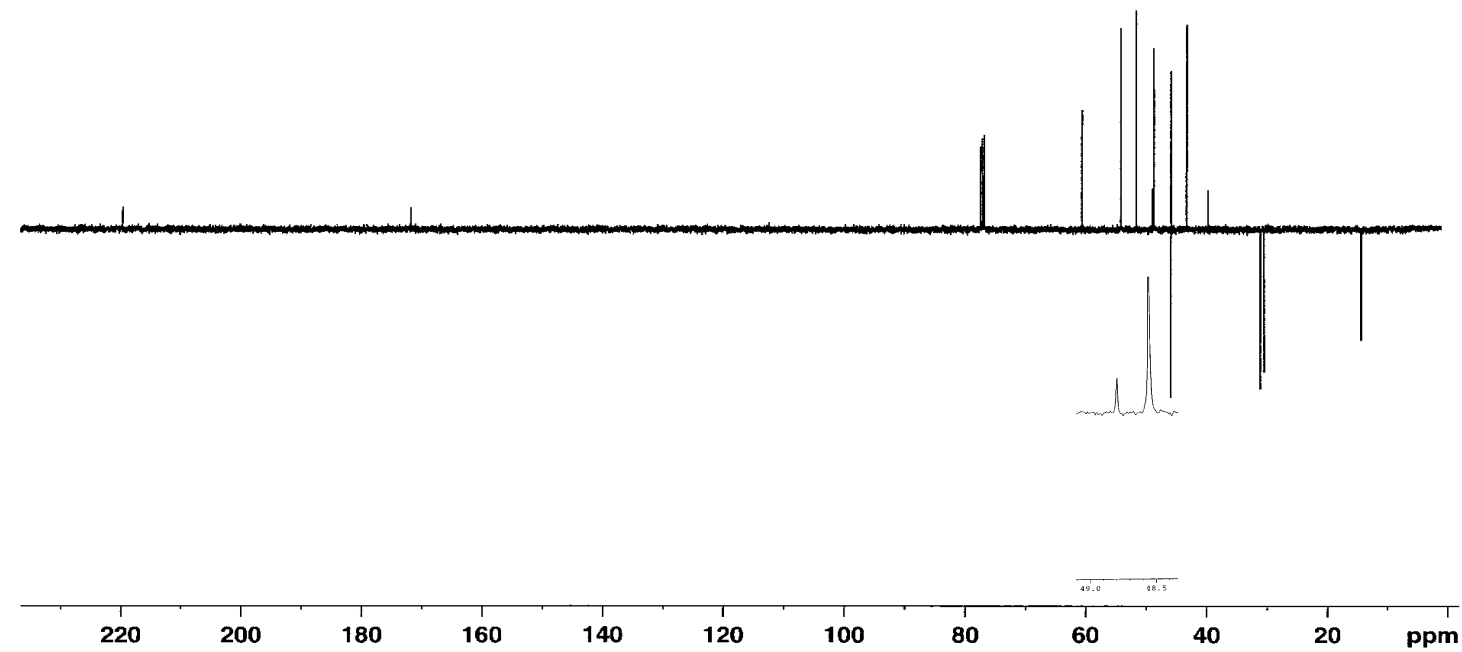


\section{Gas chromatogram of X10}
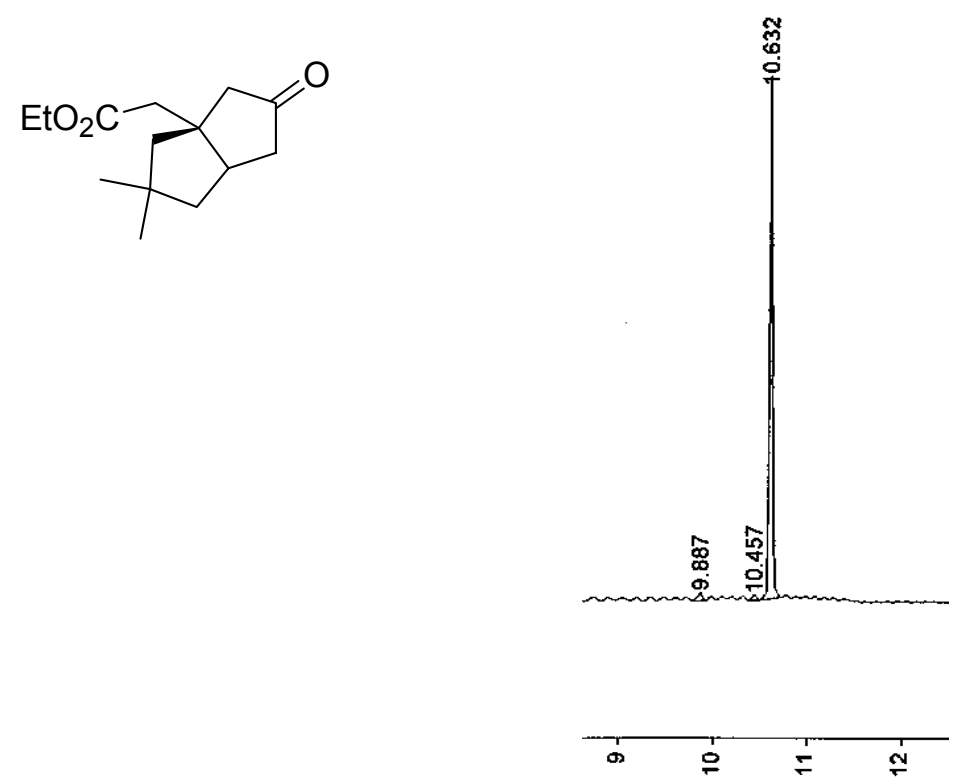

\begin{tabular}{|c|c|c|c|c|c|c|c|c|}
\hline \multirow{3}{*}{$\begin{array}{c}\text { Peak } \\
\text { No. }\end{array}$} & \multirow{3}{*}{$\begin{array}{l}\text { Peak } \\
\text { Name }\end{array}$} & \multirow{3}{*}{$\begin{array}{c}\text { Result } \\
\text { () }\end{array}$} & \multicolumn{2}{|r|}{ Time } & \multirow[b]{2}{*}{ Height } & \multicolumn{3}{|c|}{ Width } \\
\hline & & & Time & offset & & Sep. & $1 / 2$ & status \\
\hline & & & (min) & (min) & (counts) & Code & $(\sec )$ & Codes \\
\hline-- & -- & ----- & ------- & -ー-ー-ー- & ----- & $-=-$ & - & \\
\hline 1 & & 1.5749 & 9.887 & 0.000 & 2253 & BB & 3.5 & \\
\hline 2 & & 0.9458 & 10.457 & 0.000 & 1353 & $\mathrm{BP}$ & 3.6 & \\
\hline 3 & & 97.4793 & 10.632 & 0.000 & 139474 & PB & 2.1 & \\
\hline & . & 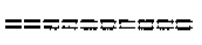 & ------ & $F=\square=r:=$ & $\Rightarrow=\Rightarrow=-=0=0=$ & ---- & & \\
\hline & Totals: & 100.0000 & & 0.000 & 143080 & & & \\
\hline
\end{tabular}


${ }^{1} \mathrm{H}$ NMR spectrum of $\mathbf{1 1}\left(400 \mathrm{MHz}, \mathrm{CDCl}_{3}\right)$

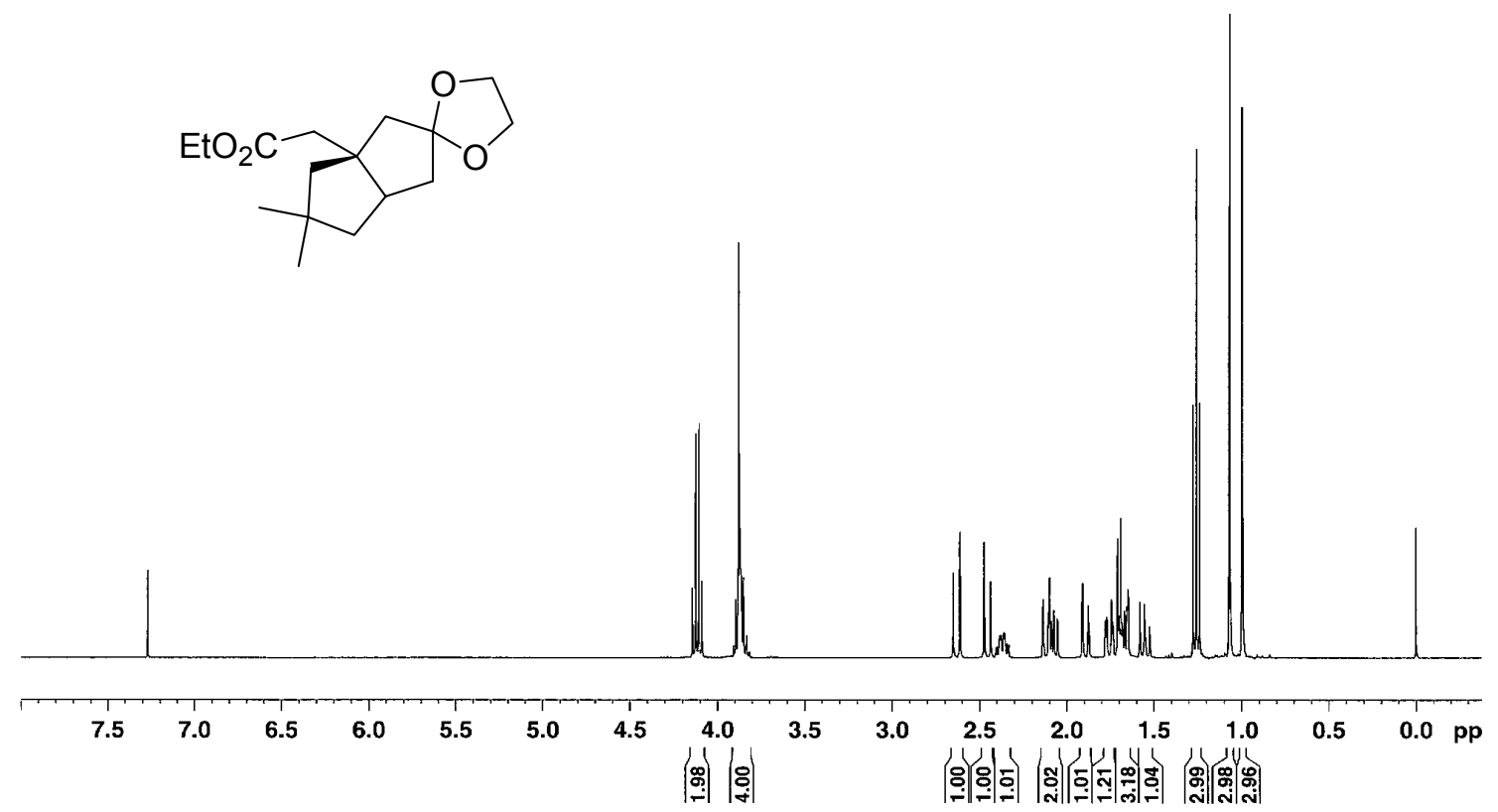

${ }^{13} \mathrm{C}$ APT NMR spectrum of $11\left(100 \mathrm{MHz}, \mathrm{CDCl}_{3}\right)$
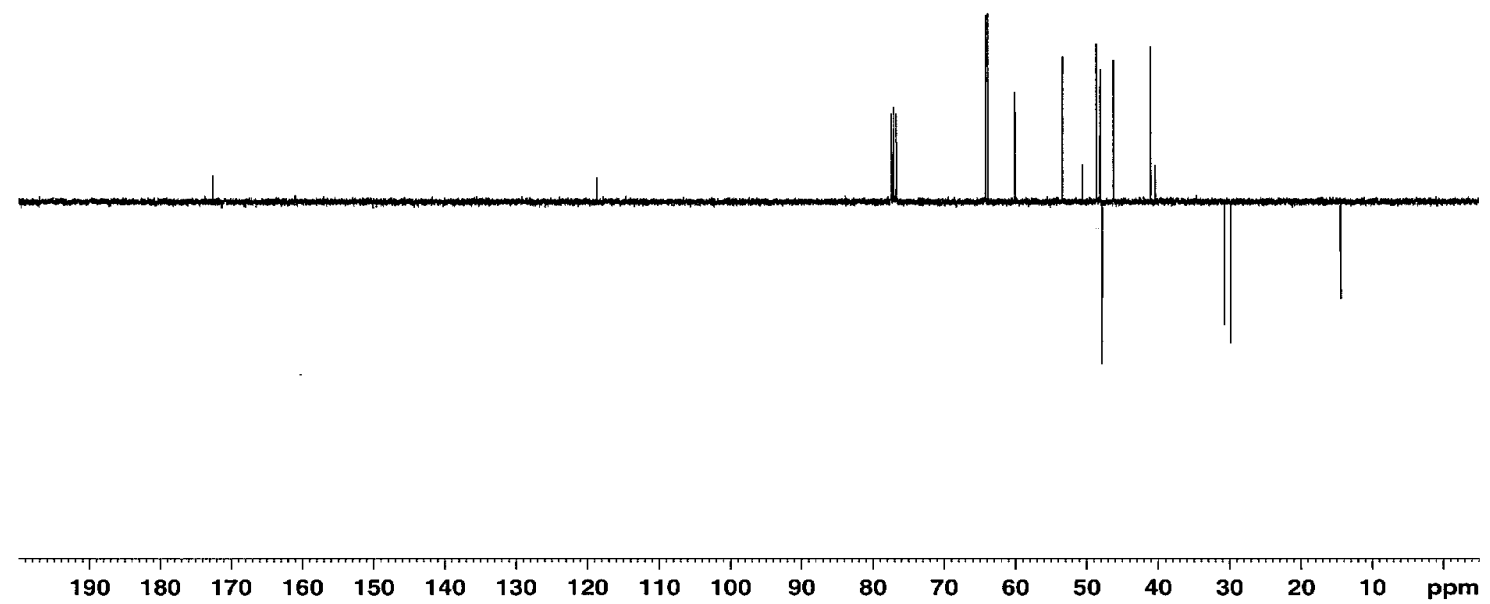


\section{Gas chromatogram of 11}<smiles>CCOC(=O)CC12CC(C)(C)CC1CC1(C2)OCCO1</smiles>

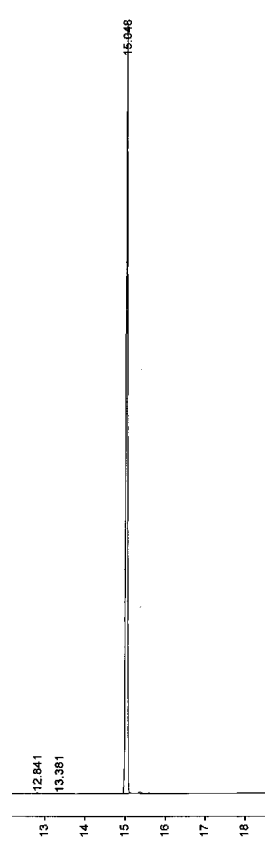

\begin{tabular}{|c|c|c|c|c|c|c|c|c|}
\hline & & & Ret. & Time & & & Width & \\
\hline $\begin{array}{c}\text { Peak } \\
\text { No. }\end{array}$ & $\begin{array}{l}\text { Peak } \\
\text { Name }\end{array}$ & $\begin{array}{c}\text { Result } \\
\text { () }\end{array}$ & $\begin{array}{l}\text { Time } \\
\text { (min) }\end{array}$ & $\begin{array}{r}\text { Offset } \\
\text { (min) }\end{array}$ & $\begin{array}{l}\text { Height } \\
\text { (counts) }\end{array}$ & $\begin{array}{l}\text { Sep. } \\
\text { Code }\end{array}$ & $\begin{array}{c}1 / 2 \\
(\sec )\end{array}$ & $\begin{array}{l}\text { Status } \\
\text { Codes }\end{array}$ \\
\hline---- & 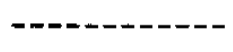 & $----\infty$ & ------ & ------- & --------- & ---- & 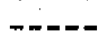 & $-\ldots$ \\
\hline 1 & & 0.1074 & 12.841 & 0.000 & 209 & BB & 2.8 & \\
\hline 2 & & 0.0219 & 13.381 & 0.000 & 43 & $\mathrm{BB}$ & 2.7 & \\
\hline 3 & & 99.8707 & 15.048 & 0.000 & 193973 & $\mathrm{BB}$ & 2.8 & \\
\hline & 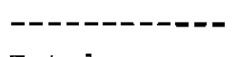 & $========$ & $-\ldots-n$ & $=======$ & $=\ddot{=}=\ddot{=}==0=$ & -- & & \\
\hline & Totals: & 100.0000 & & 0.000 & 194225 & & & \\
\hline
\end{tabular}


${ }^{1} \mathrm{H}$ NMR spectrum of $12\left(400 \mathrm{MHz}, \mathrm{CDCl}_{3}\right)$

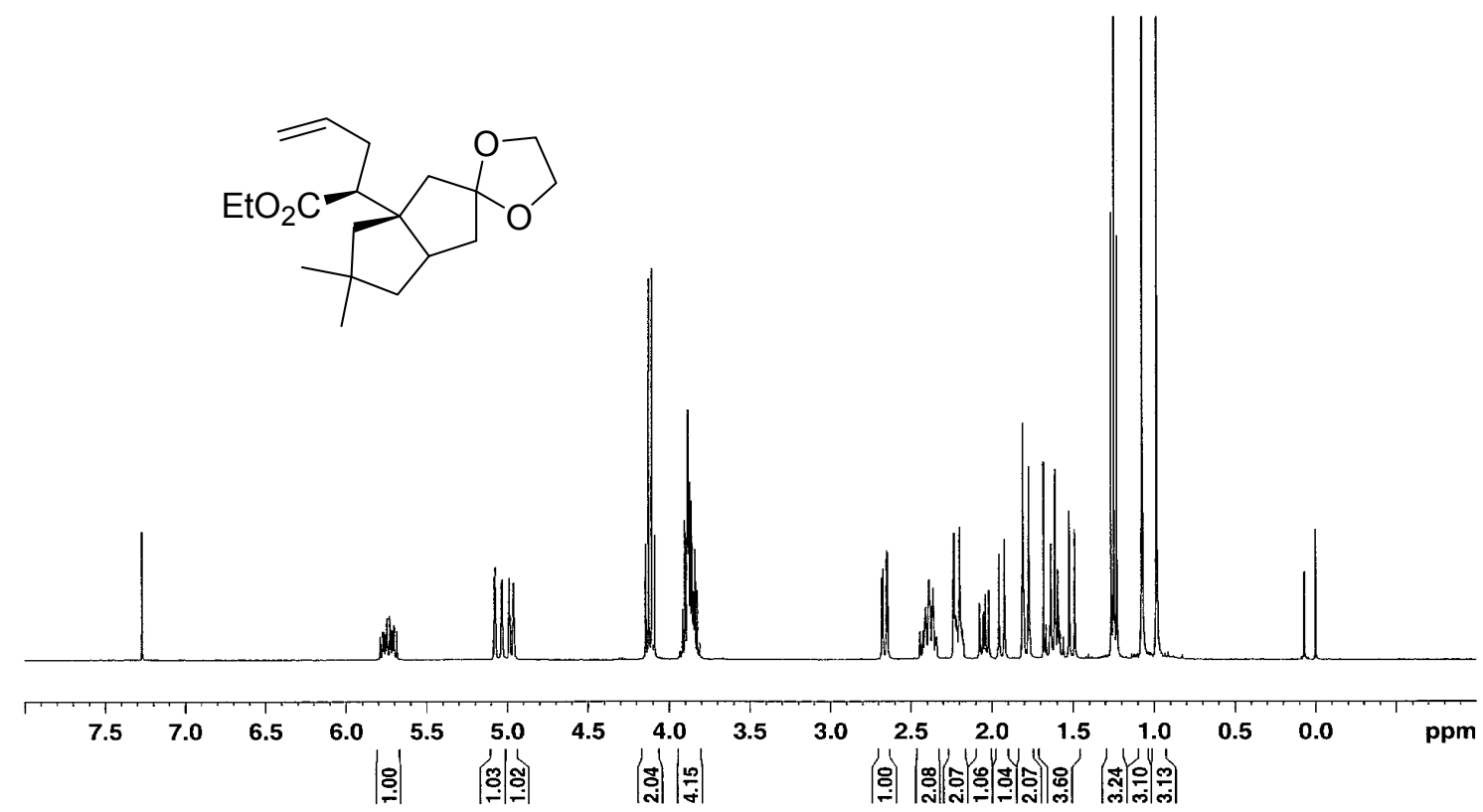

${ }^{13} \mathrm{C}$ APT NMR spectrum of $12\left(100 \mathrm{MHz}, \mathrm{CDCl}_{3}\right)$

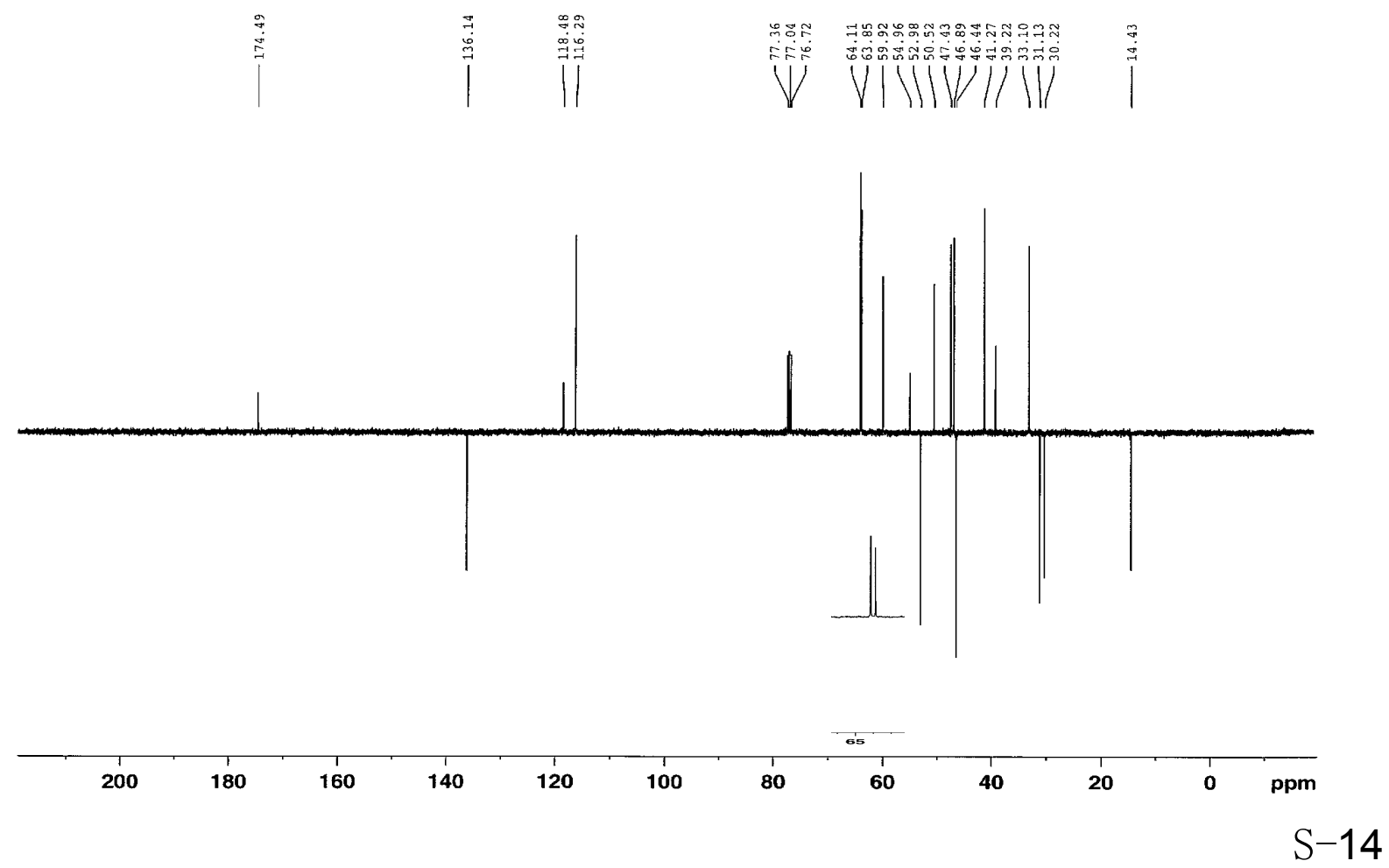




\section{Gas chromatogram of 12}<smiles>C=CC[C@@H](COCC)[C@]12CC(C)(C)CC1CC1(C2)OCCO1</smiles>

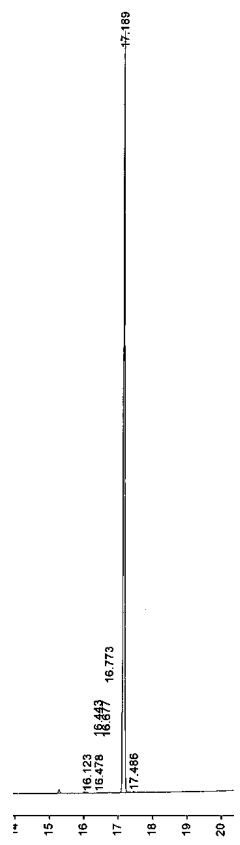

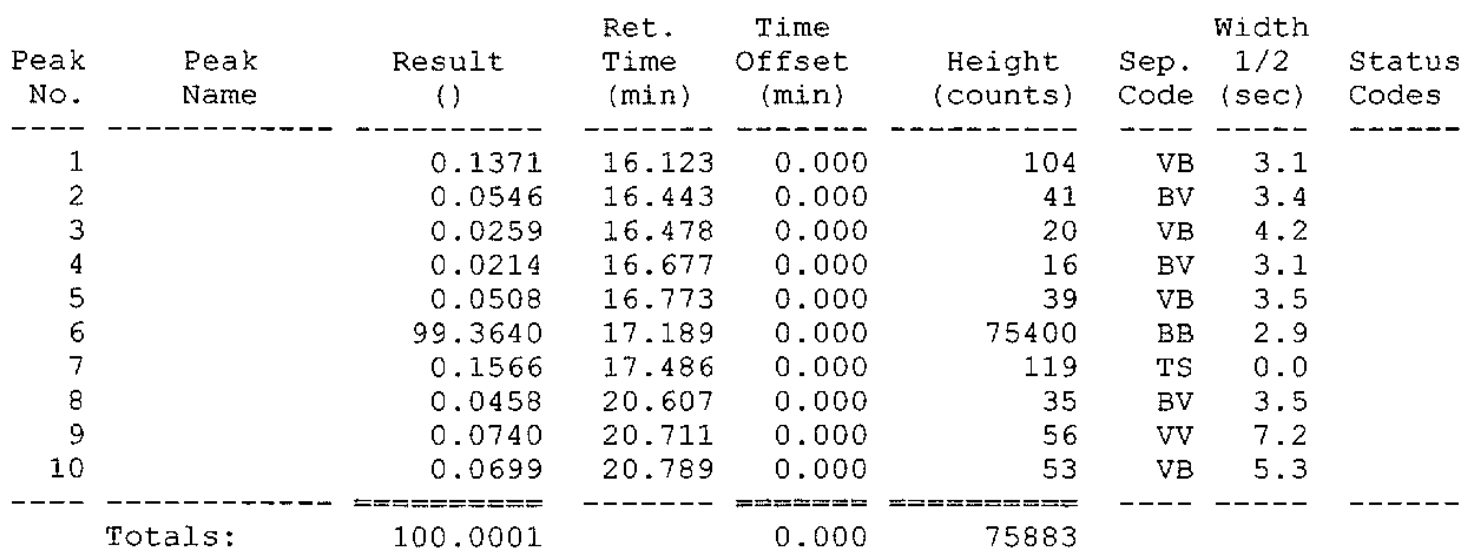


${ }^{1} \mathrm{H}$ NMR spectrum of $\mathbf{1 3}\left(400 \mathrm{MHz}, \mathrm{CDCl}_{3}\right)$

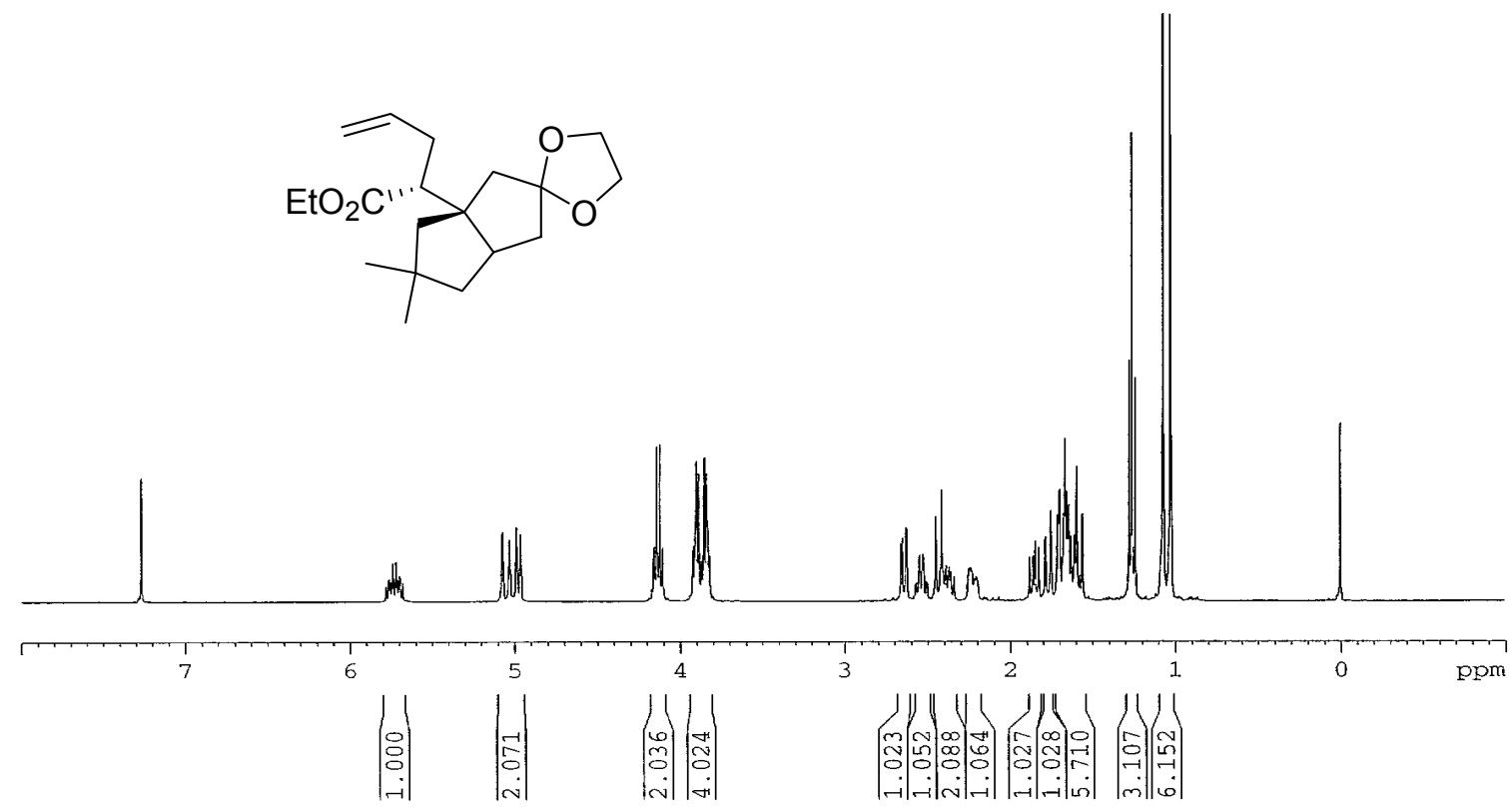

${ }^{13} \mathrm{C}$ APT NMR spectrum of $13\left(100 \mathrm{MHz}, \mathrm{CDCl}_{3}\right)$
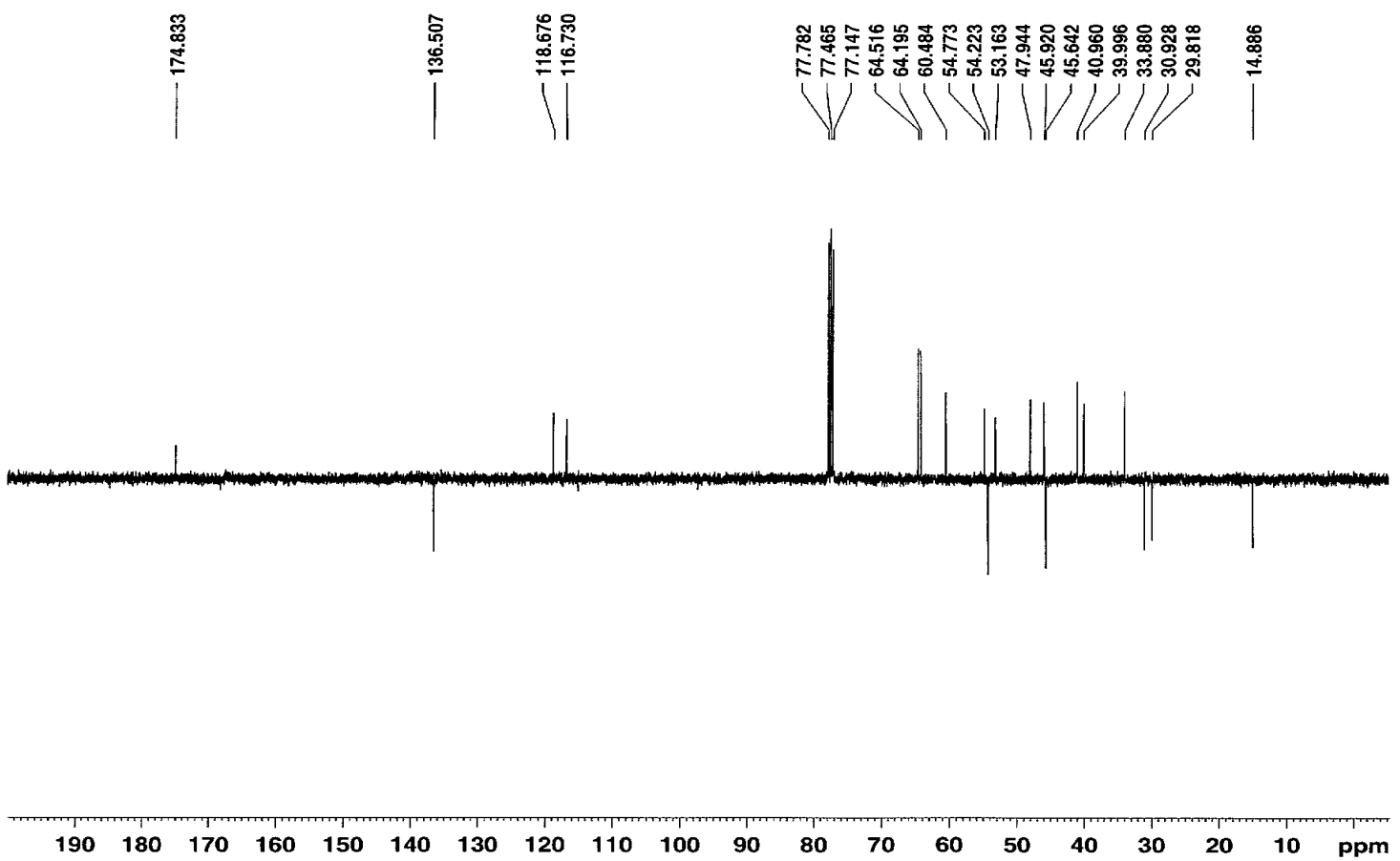


\section{Gas chromatogram of 13}
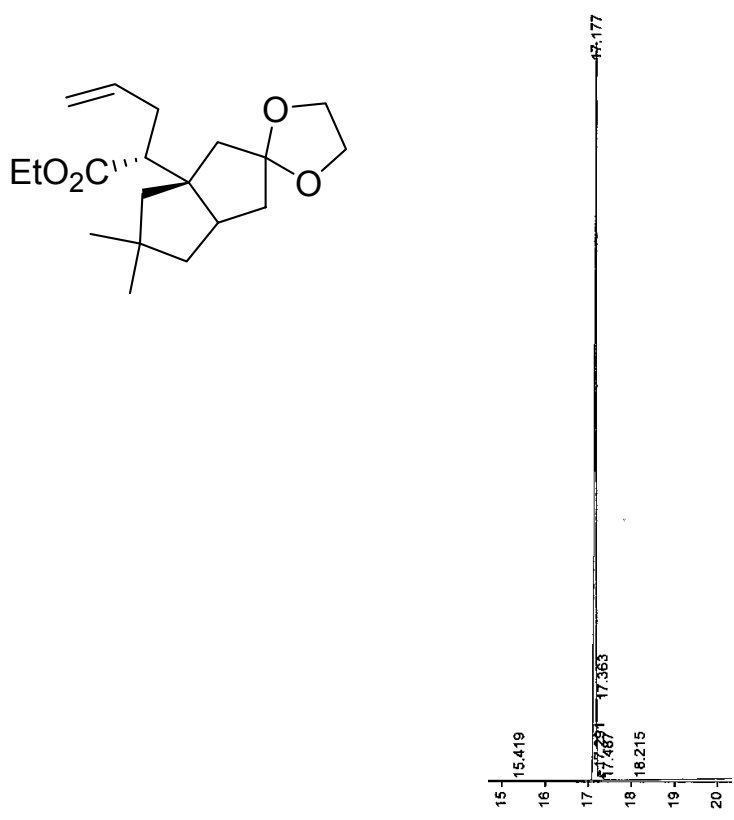

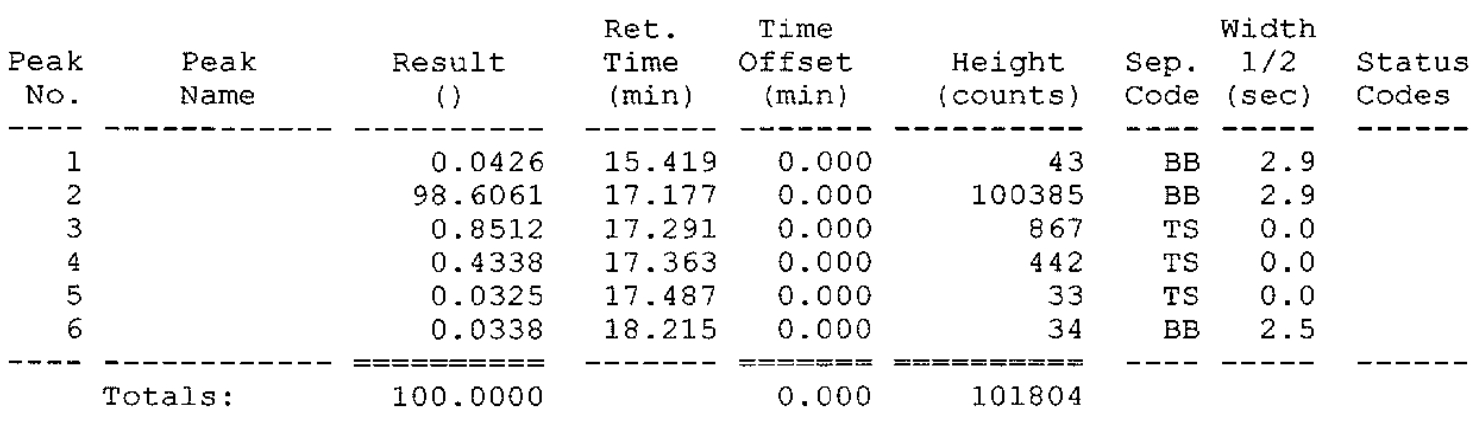


${ }^{1} \mathrm{H}$ NMR spectrum of $24\left(400 \mathrm{MHz}, \mathrm{CDCl}_{3}\right)$

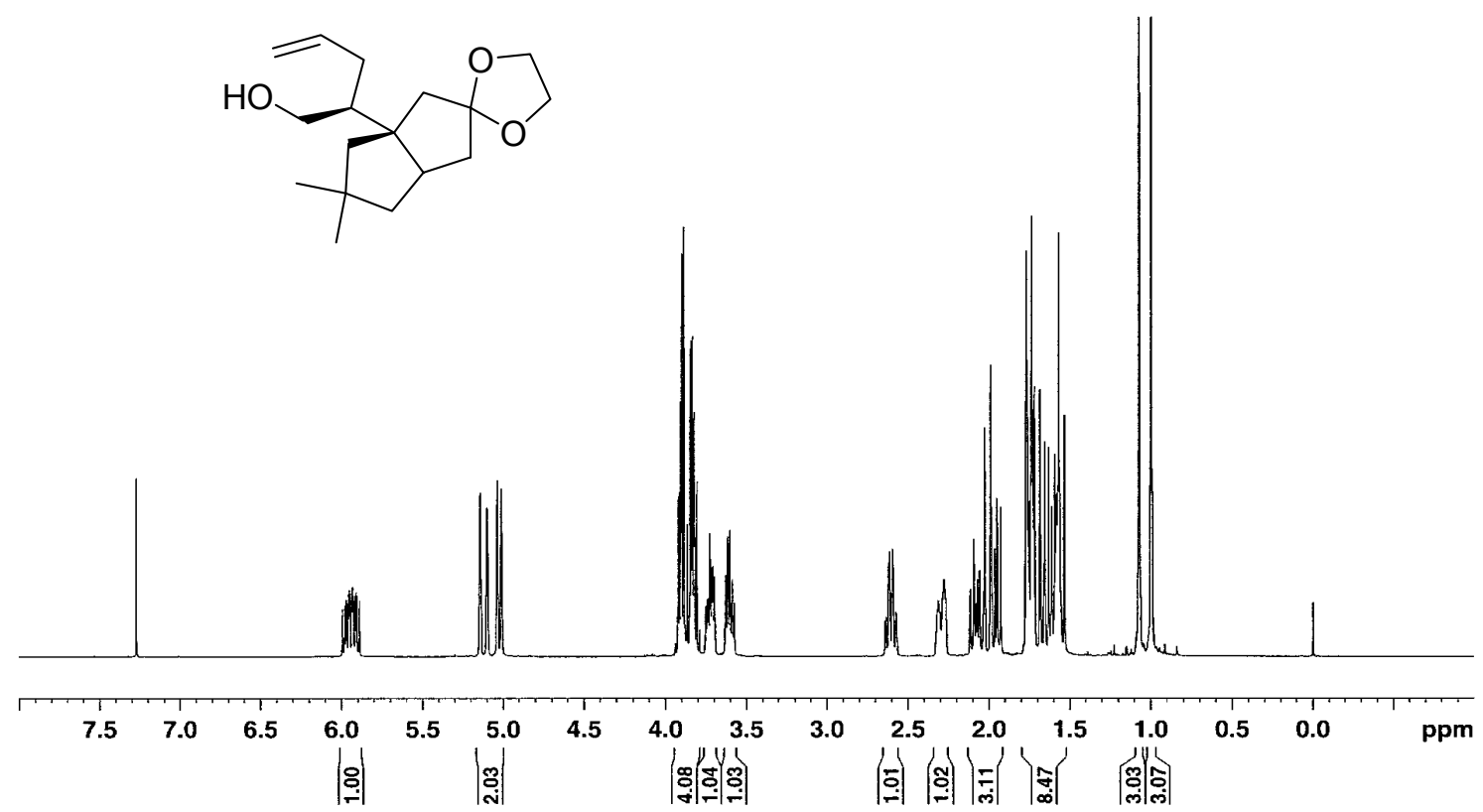

${ }^{13} \mathrm{C}$ APT NMR spectrum of $24\left(100 \mathrm{MHz}, \mathrm{CDCl}_{3}\right)$
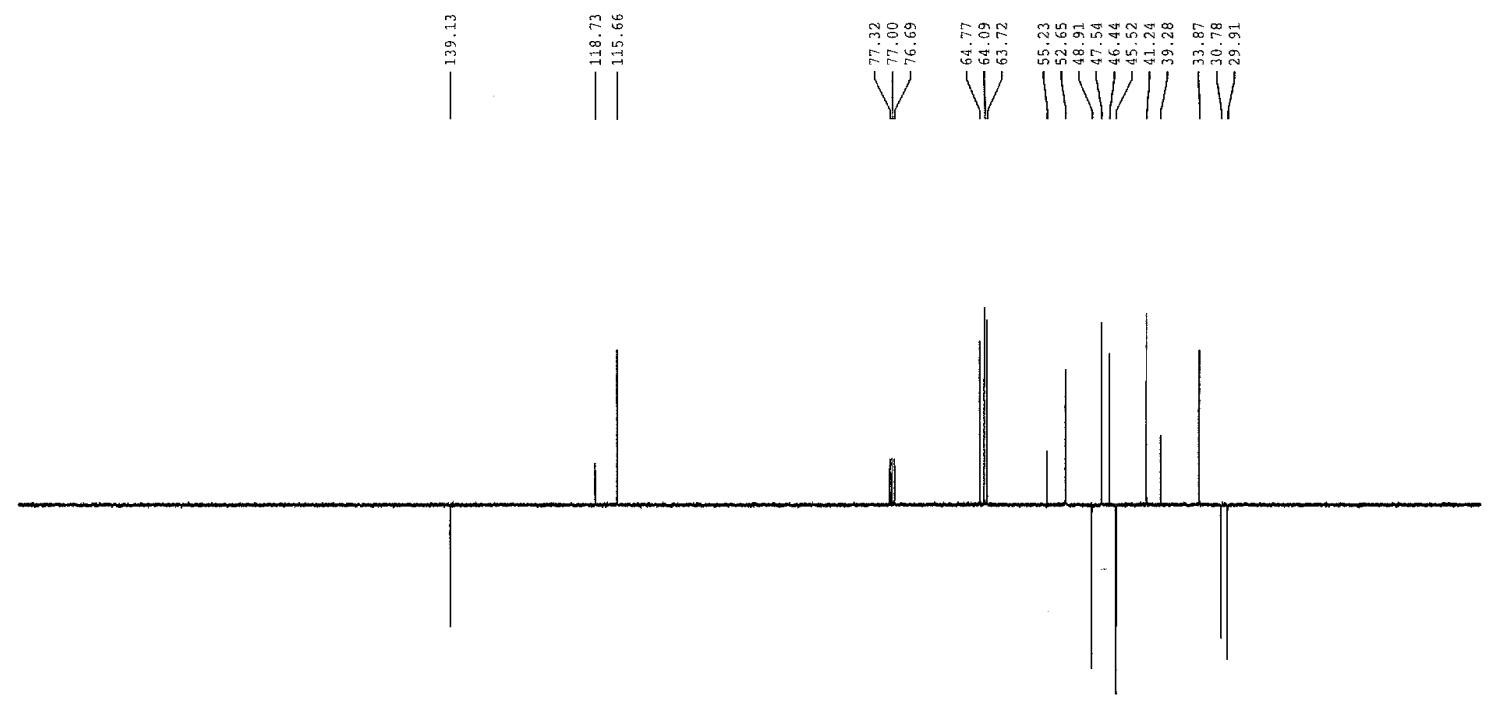

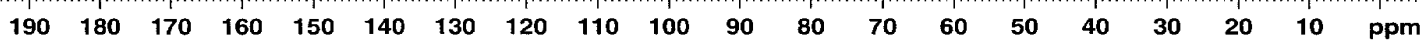


${ }^{1} \mathrm{H}$ NMR spectrum of $25\left(400 \mathrm{MHz}, \mathrm{CDCl}_{3}\right)$

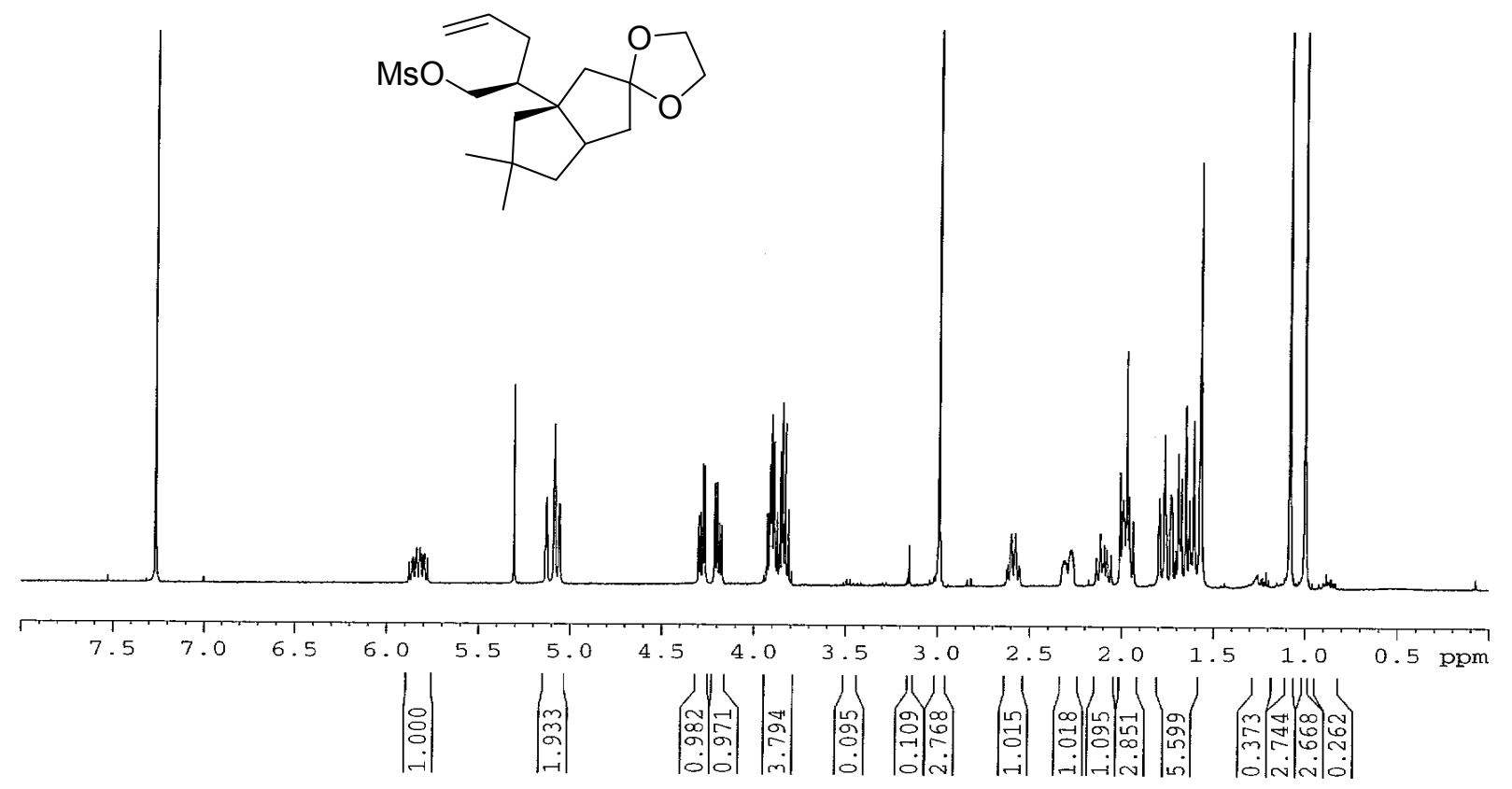


${ }^{1} \mathrm{H}$ NMR spectrum of $\mathbf{1 8}\left(400 \mathrm{MHz}, \mathrm{CDCl}_{3}\right)$

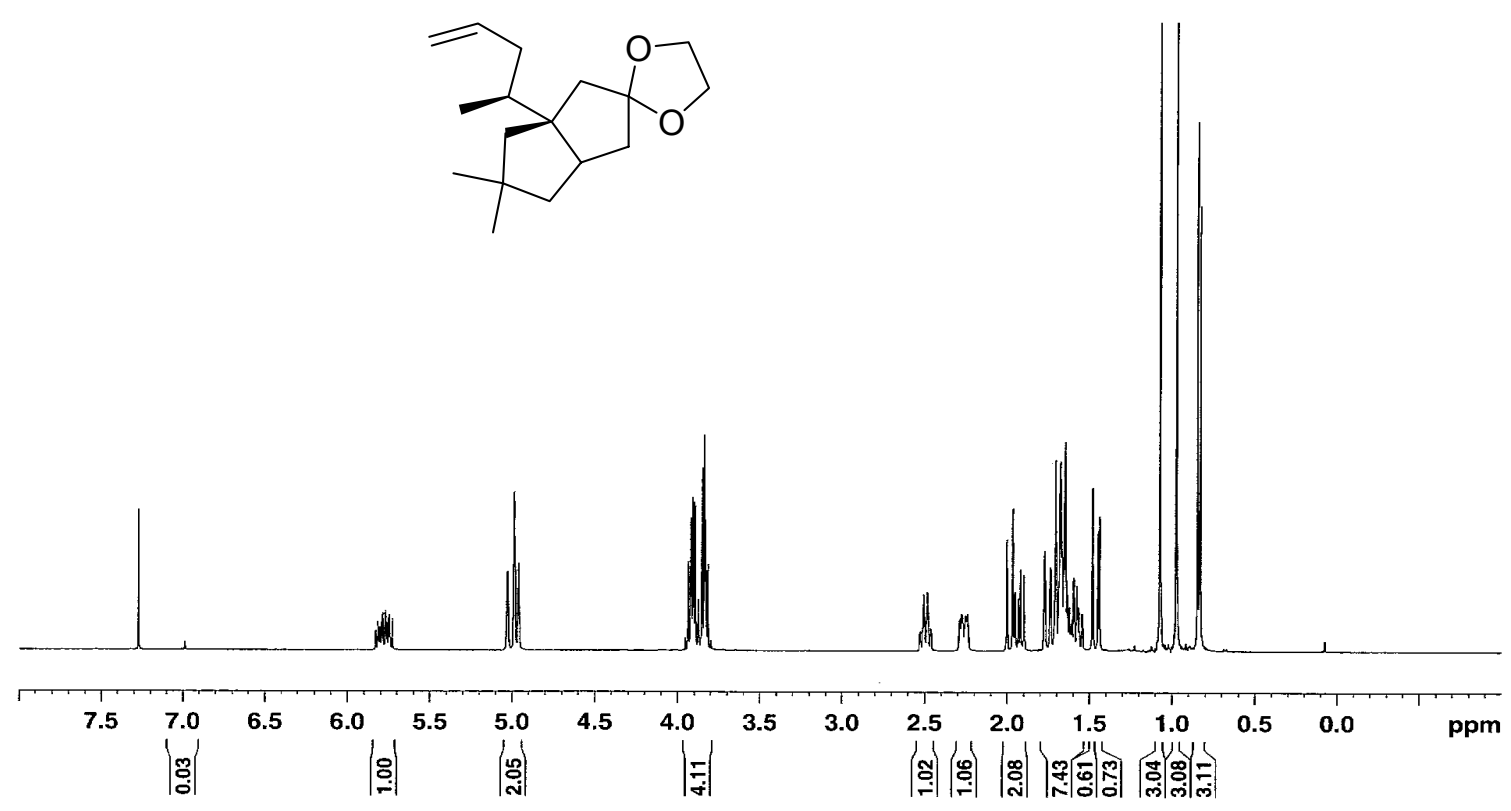

${ }^{13} \mathrm{C}$ APT NMR spectrum of $\mathbf{1 8}\left(100 \mathrm{MHz}, \mathrm{CDCl}_{3}\right)$
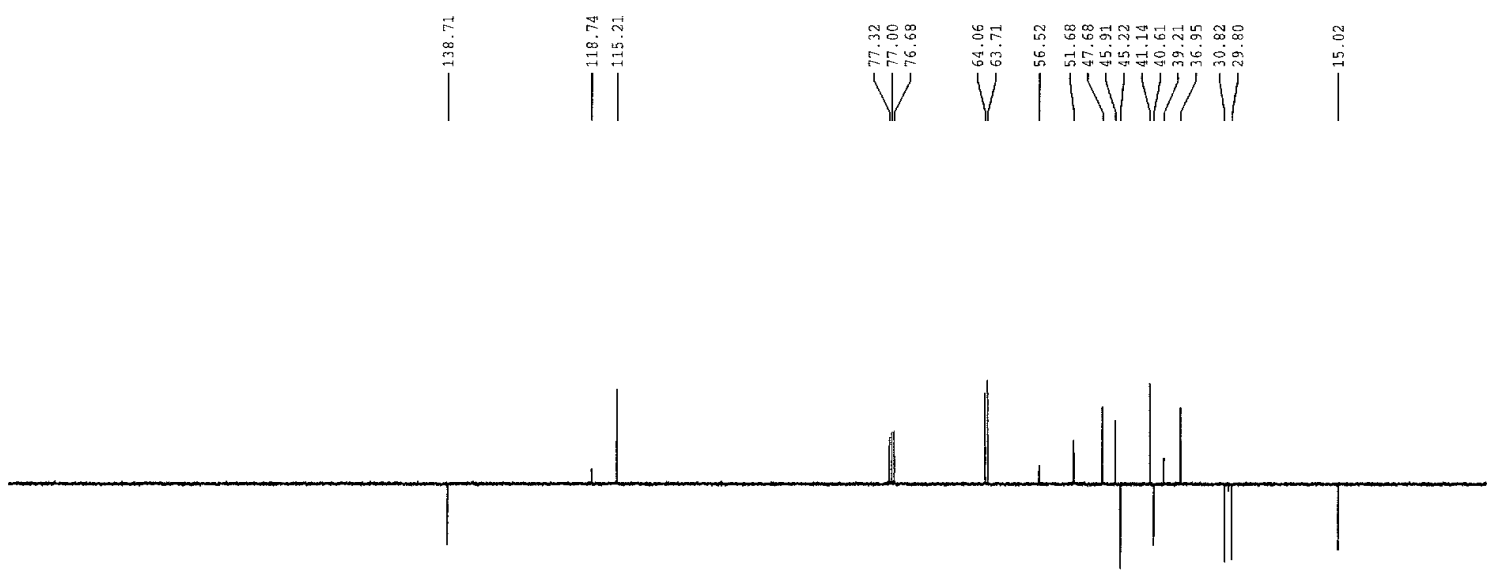

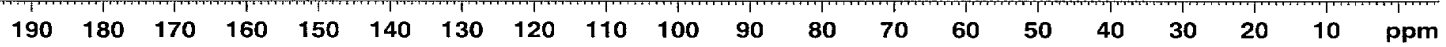



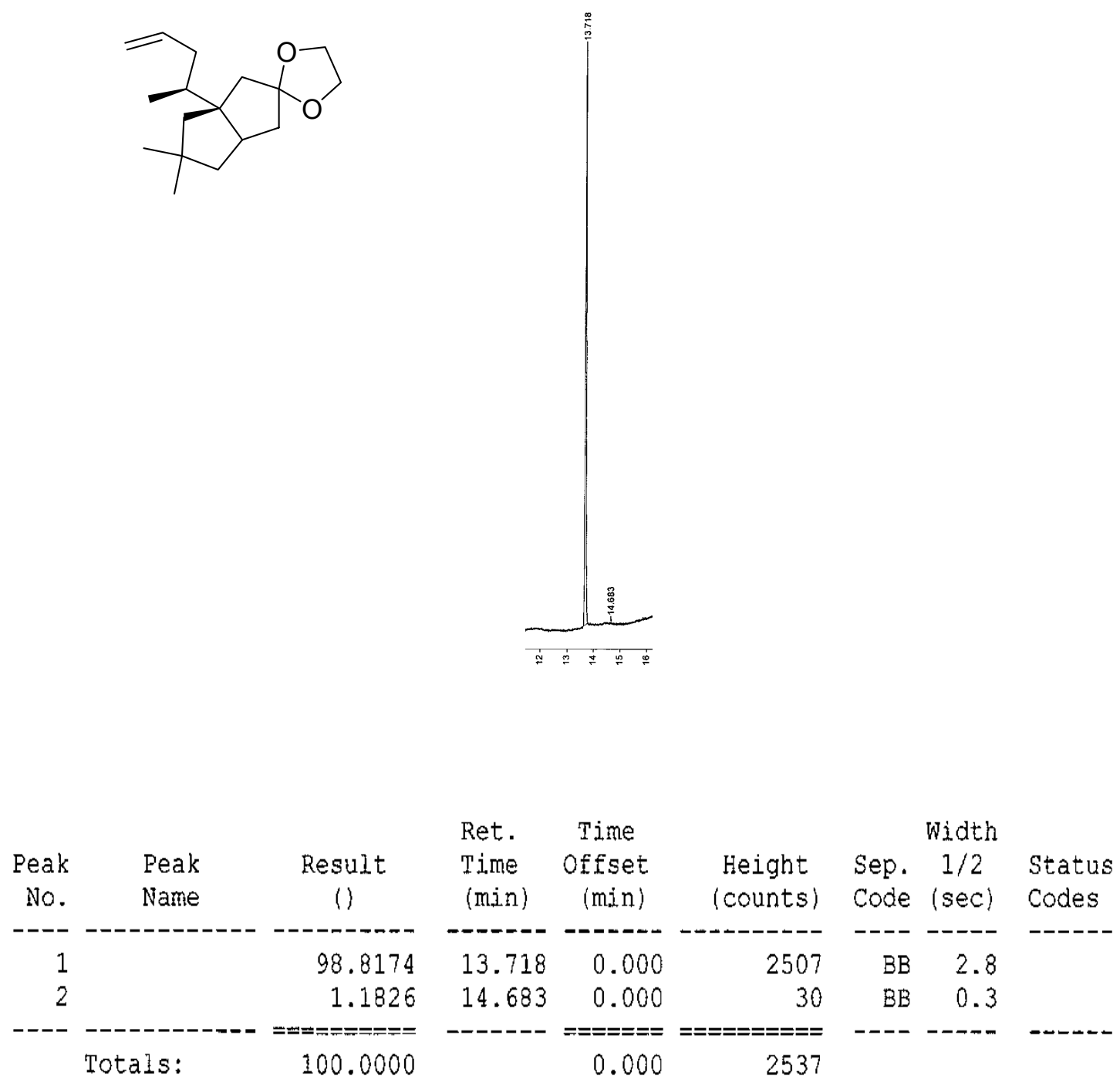
${ }^{1} \mathrm{H}$ NMR spectrum of $19\left(400 \mathrm{MHz}, \mathrm{CDCl}_{3}\right)$

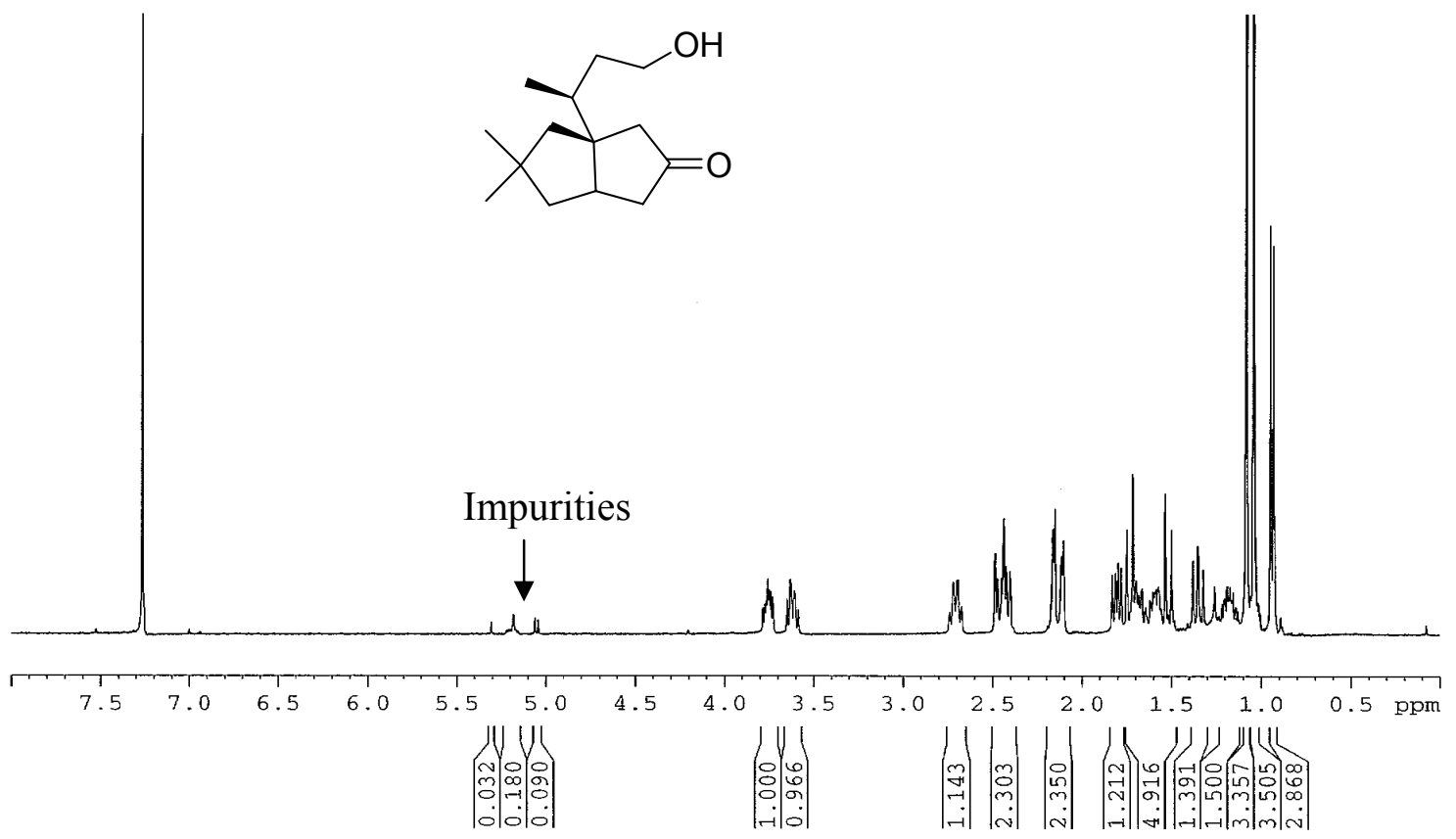


${ }^{1} \mathrm{H}$ NMR spectrum of $20\left(400 \mathrm{MHz}, \mathrm{CDCl}_{3}\right)$
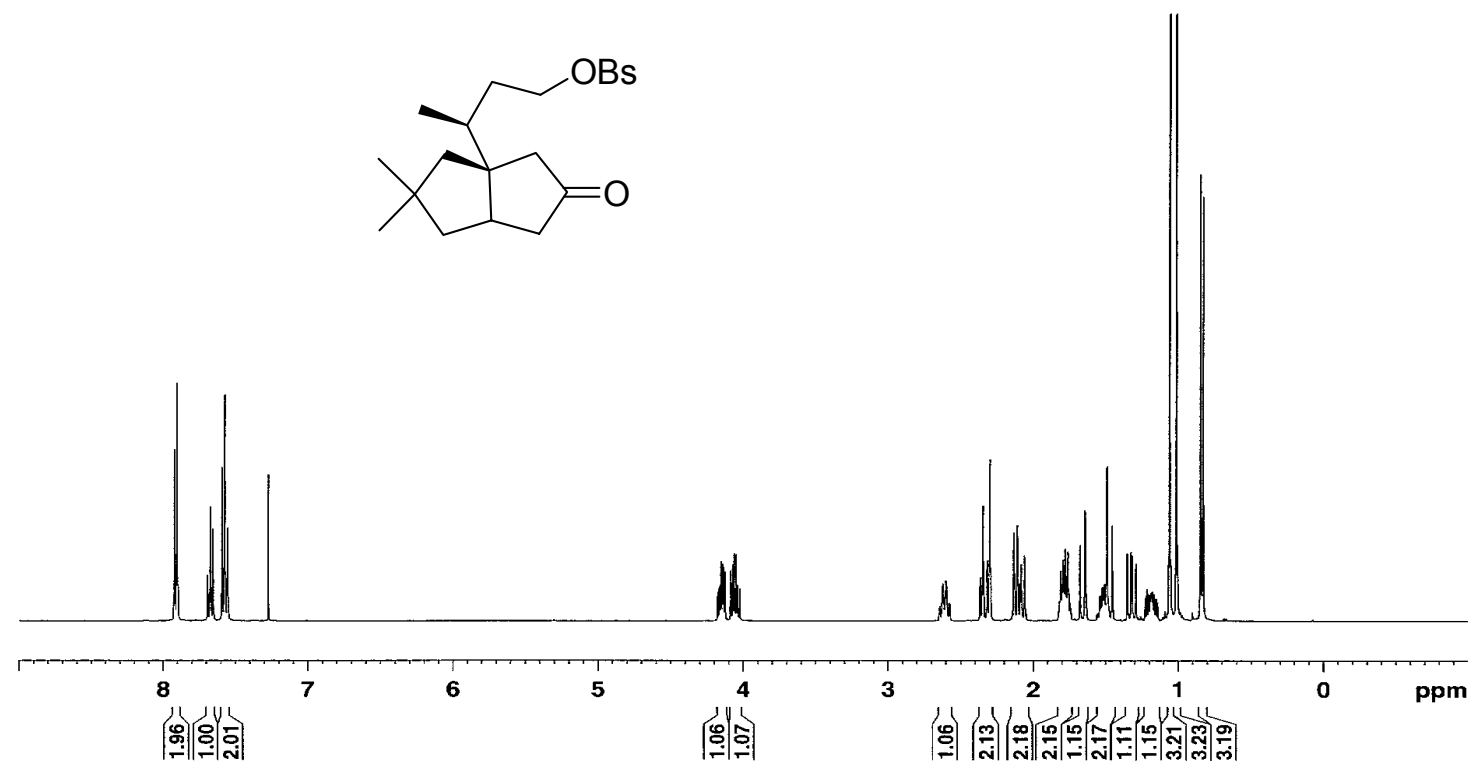

遂司

:

${ }^{13} \mathrm{C}$ APT NMR spectrum of $20\left(100 \mathrm{MHz}, \mathrm{CDCl}_{3}\right)$
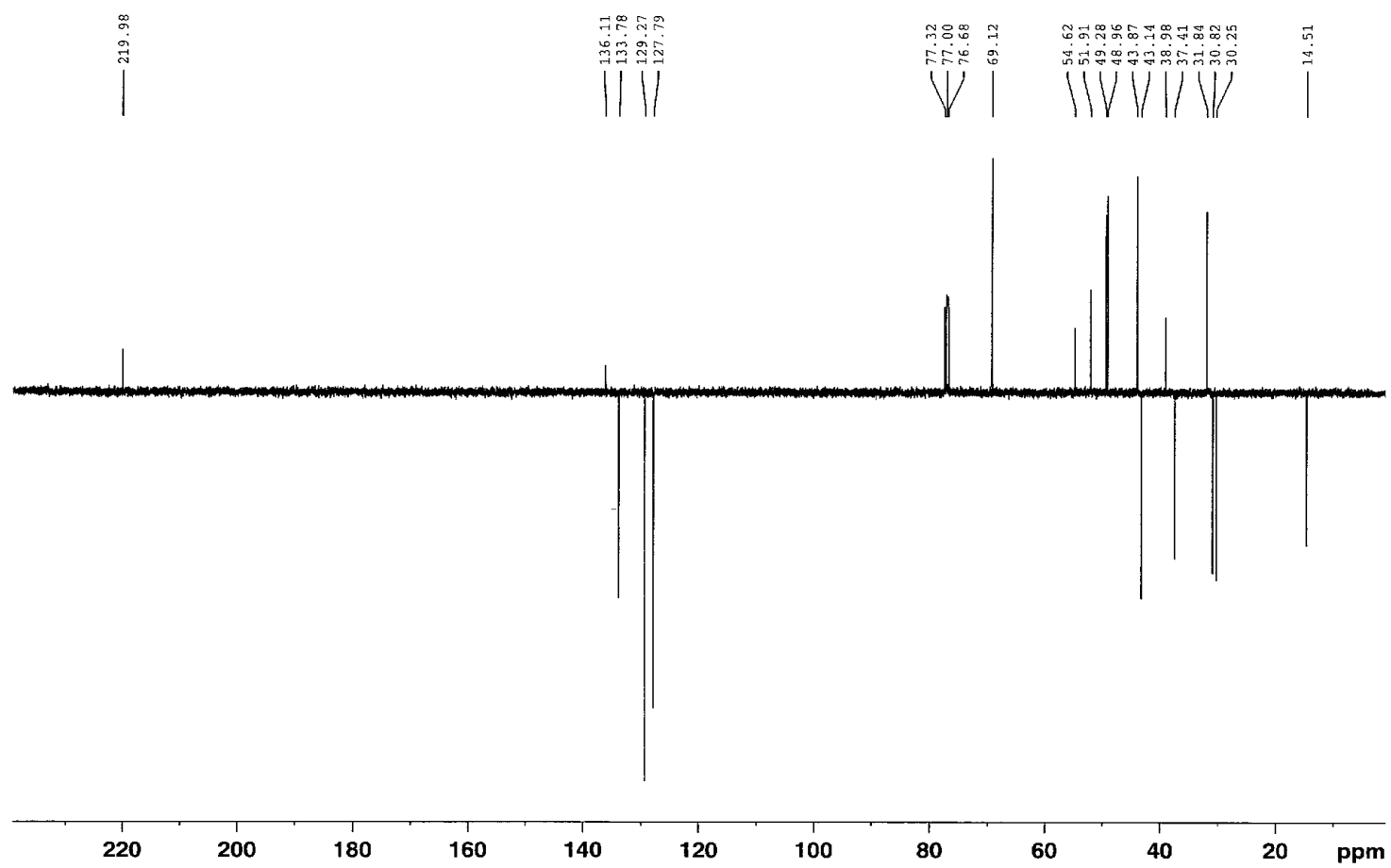
${ }^{1} \mathrm{H}$ NMR spectrum of $21\left(400 \mathrm{MHz}, \mathrm{CDCl}_{3}\right)$

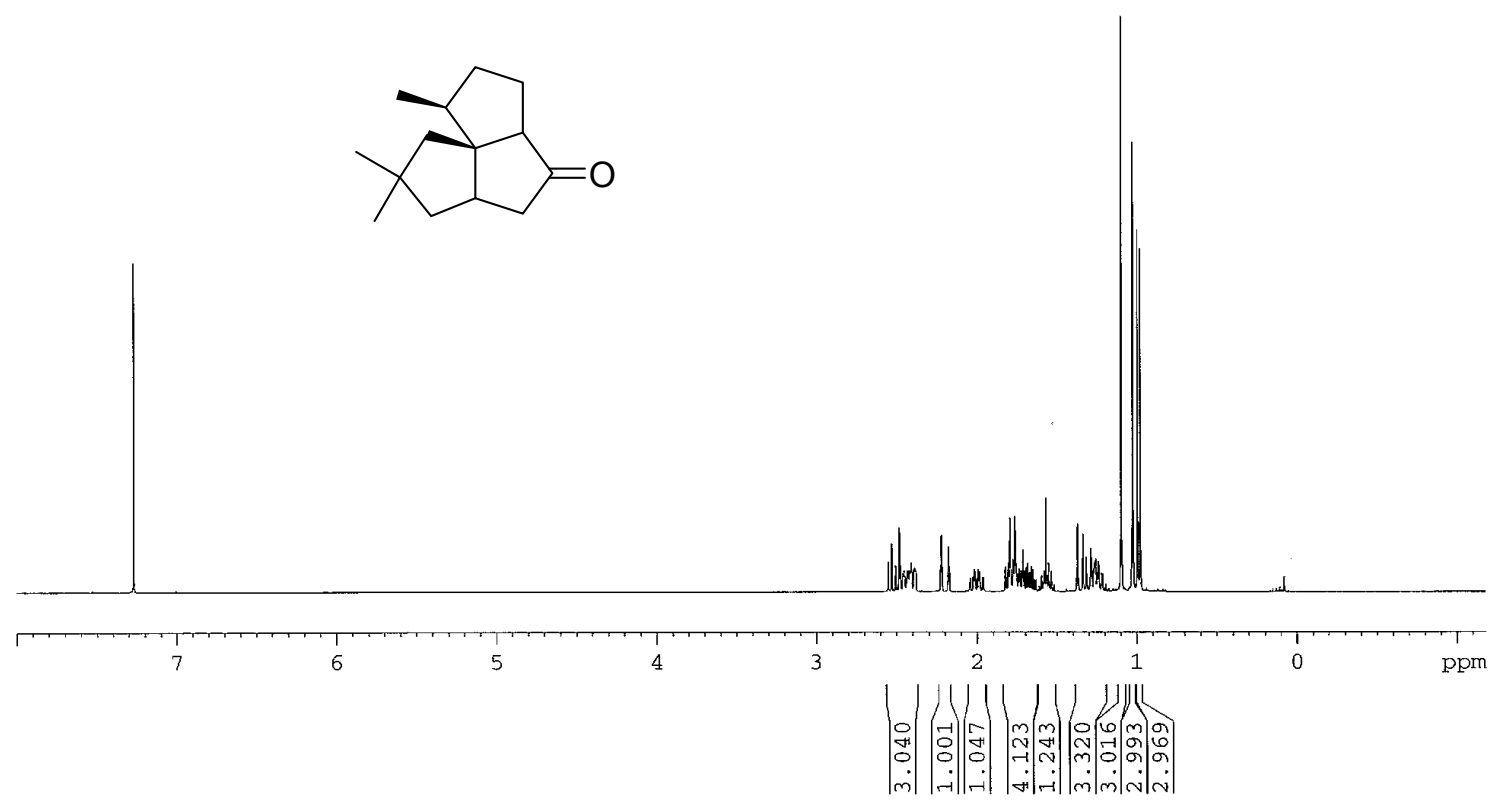

${ }^{13} \mathrm{C}$ APT NMR spectrum of $21\left(100 \mathrm{MHz}, \mathrm{CDCl}_{3}\right)$

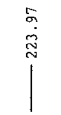

V|
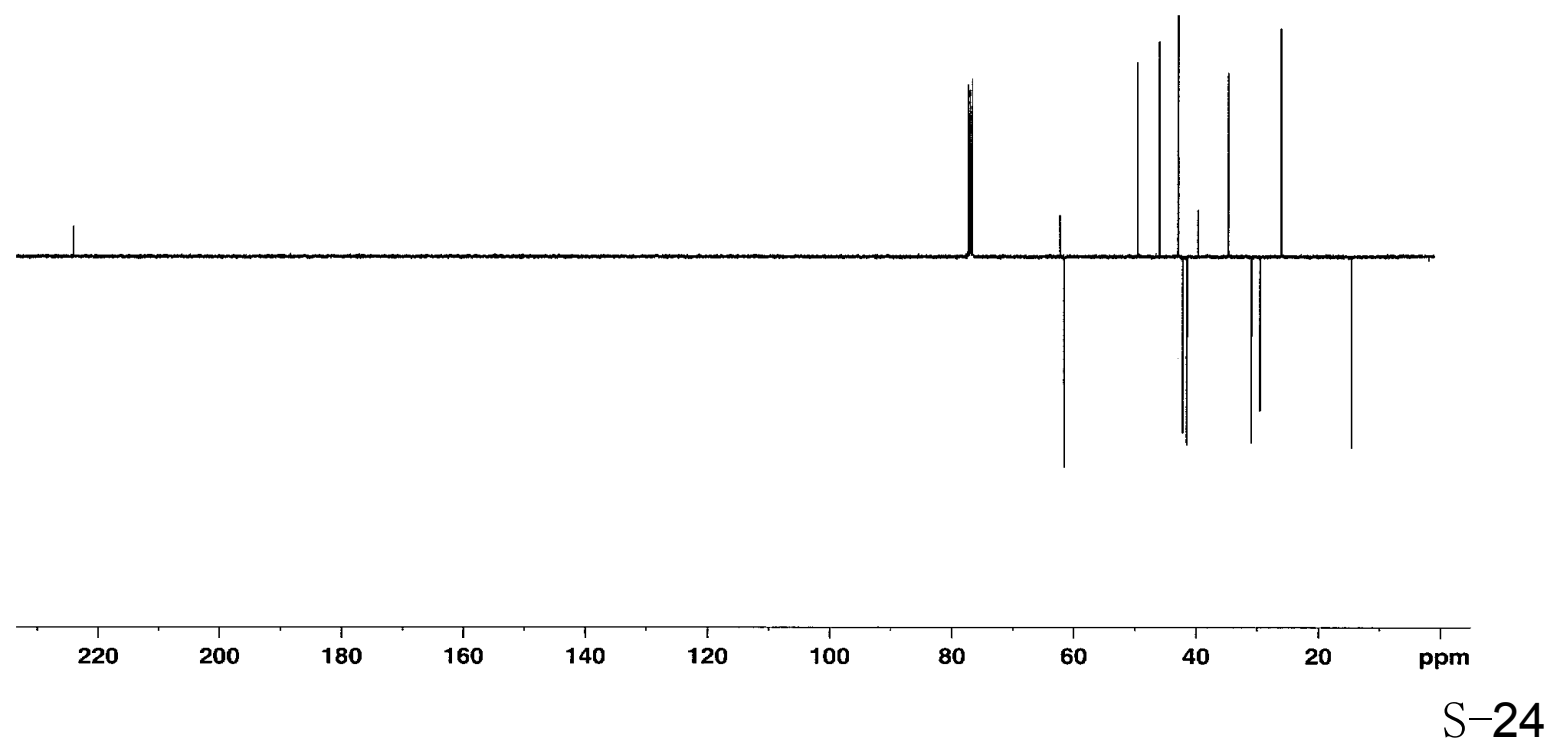


\section{Gas chromatogram of $\mathbf{2 1}$}
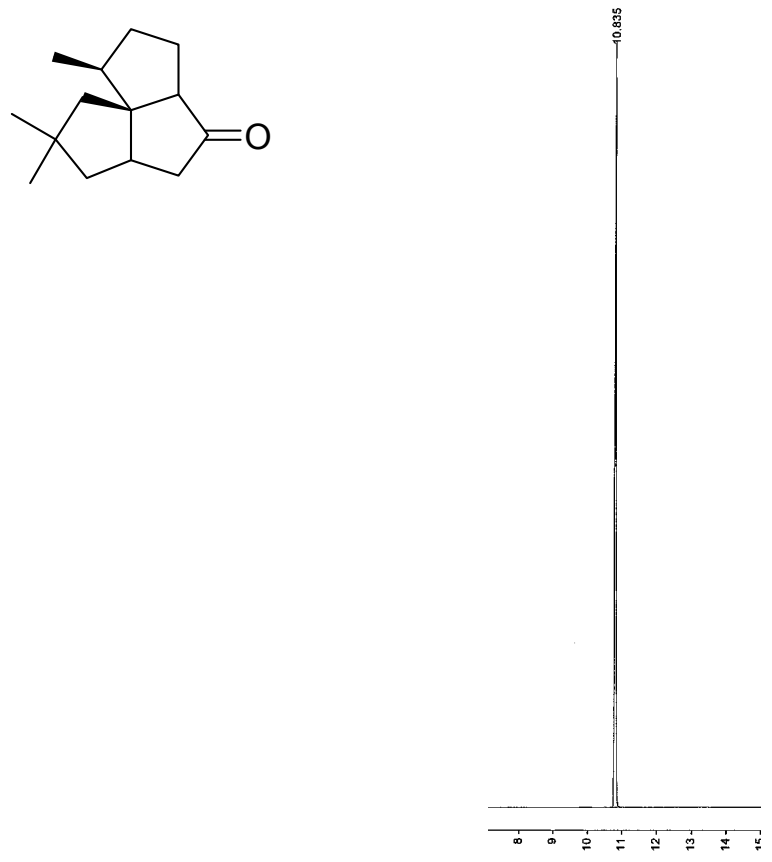

\begin{tabular}{|c|c|c|c|c|c|c|c|c|}
\hline $\begin{array}{r}\text { Peak } \\
\text { No. }\end{array}$ & $\begin{array}{l}\text { Peak } \\
\text { Name }\end{array}$ & $\begin{array}{c}\text { Result } \\
\text { () }\end{array}$ & $\begin{array}{l}\text { Ret. } \\
\text { Time } \\
\text { (min) }\end{array}$ & $\begin{array}{l}\text { Time } \\
\text { offset } \\
\text { (min) }\end{array}$ & $\begin{array}{c}\text { Height } \\
\text { (counts) }\end{array}$ & $\begin{array}{l}\text { Sep. } \\
\text { Code }\end{array}$ & $\begin{array}{c}\text { Width } \\
1 / 2 \\
\text { (sec) }\end{array}$ & $\begin{array}{l}\text { Status } \\
\text { Codes }\end{array}$ \\
\hline & 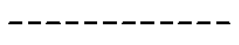 & --- & -- & $---\pi$ & & - & & \\
\hline 1 & & 100.0000 & 10.835 & 0.000 & 73360 & $B B$ & 2.7 & \\
\hline & Totals: & $\begin{array}{r}======== \\
100.0000\end{array}$ & ------- & $\begin{array}{r}=\pi=== \\
0.000\end{array}$ & $\begin{array}{r}======= \\
73360\end{array}$ & & & \\
\hline
\end{tabular}


${ }^{1} \mathrm{H}$ NMR spectrum of $22\left(400 \mathrm{MHz}, \mathrm{CDCl}_{3}\right)$
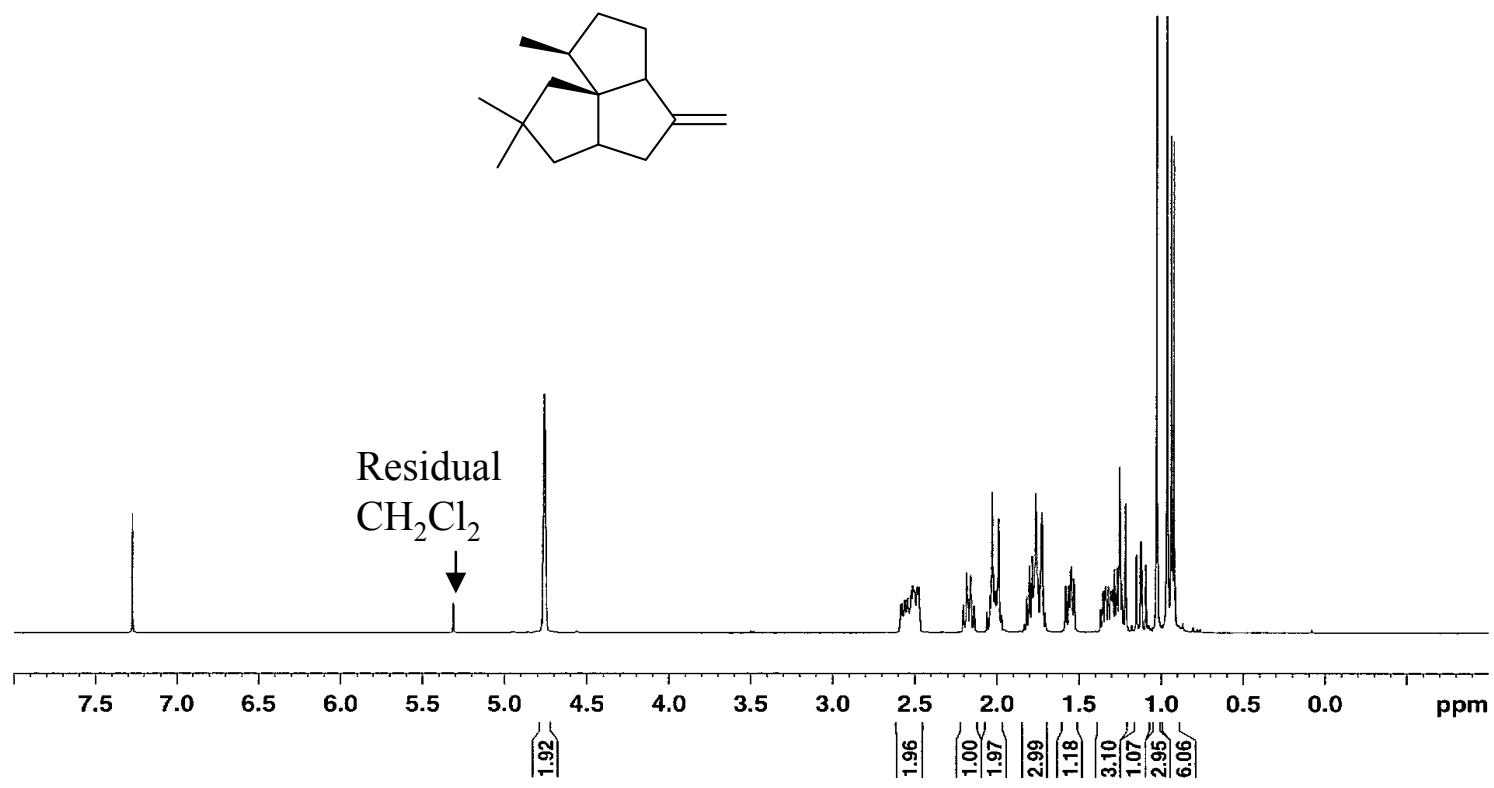

${ }^{13} \mathrm{C}$ APT NMR spectrum of $22\left(100 \mathrm{MHz}, \mathrm{CDCl}_{3}\right)$
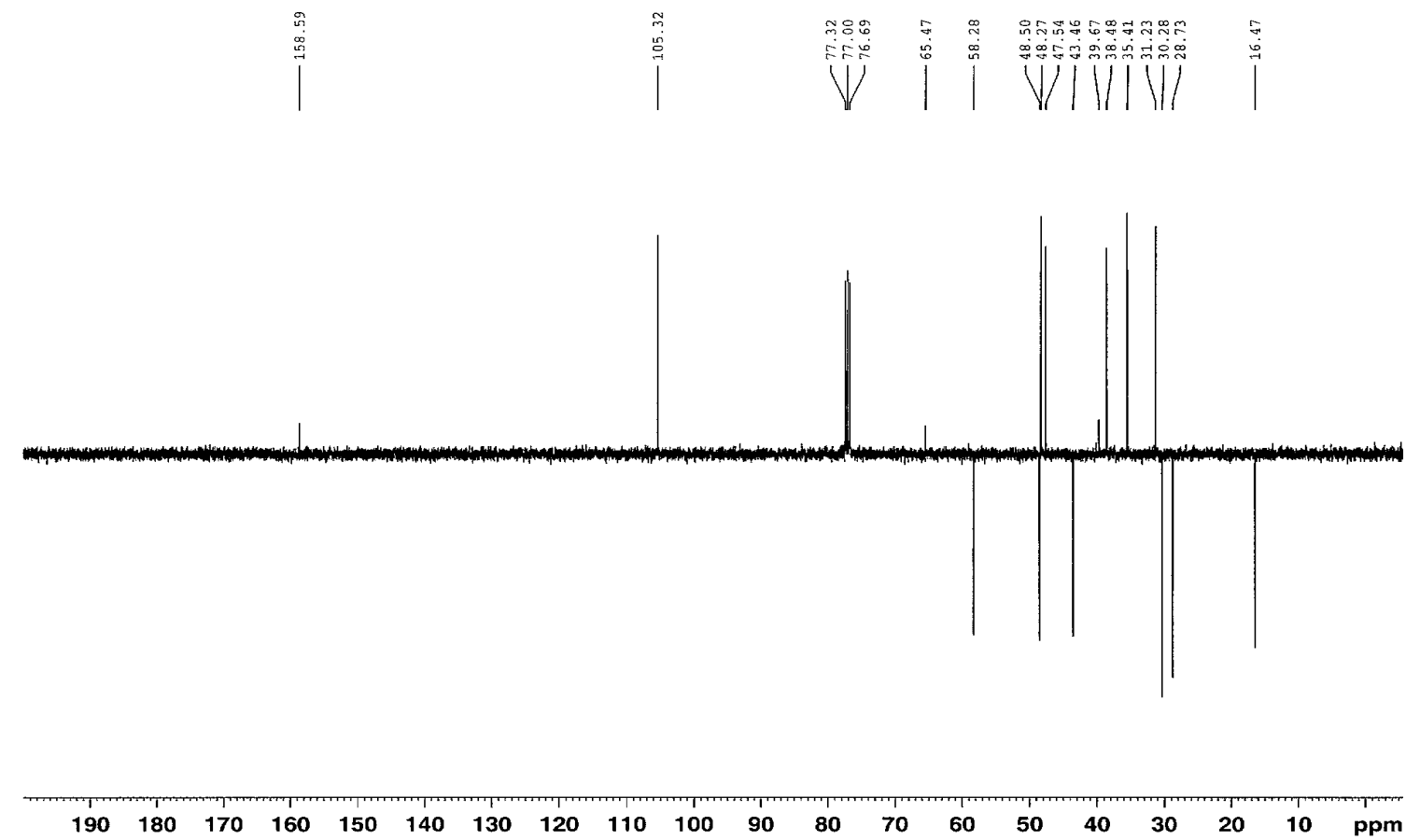
${ }^{1} \mathrm{H}$ NMR spectrum of (-)-1 (400 MHz, $\mathrm{CDCl}_{3}$ )
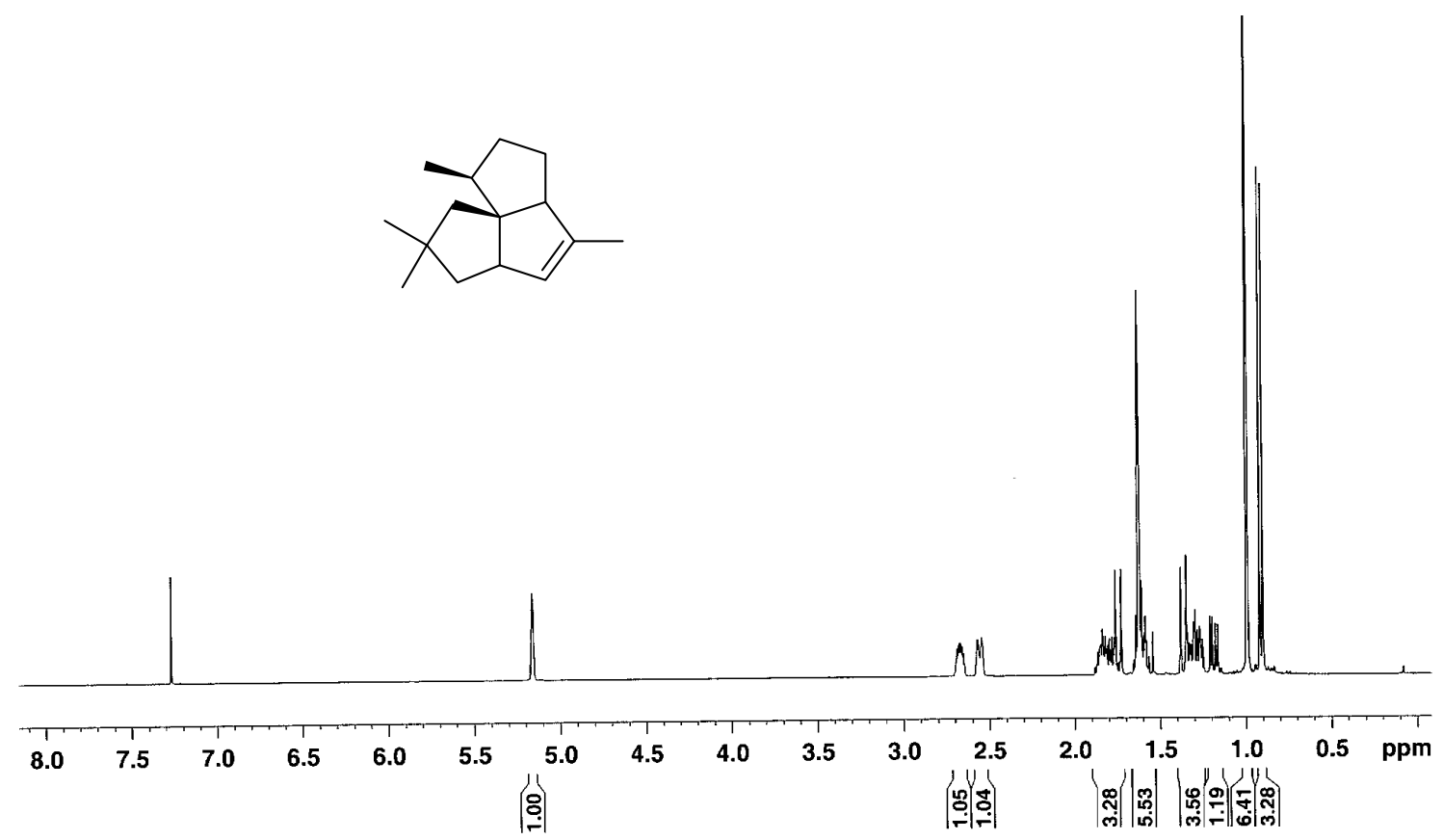

${ }^{13} \mathrm{C}$ APT NMR spectrum of (-)-1(100 MHz, $\left.\mathrm{CDCl}_{3}\right)$
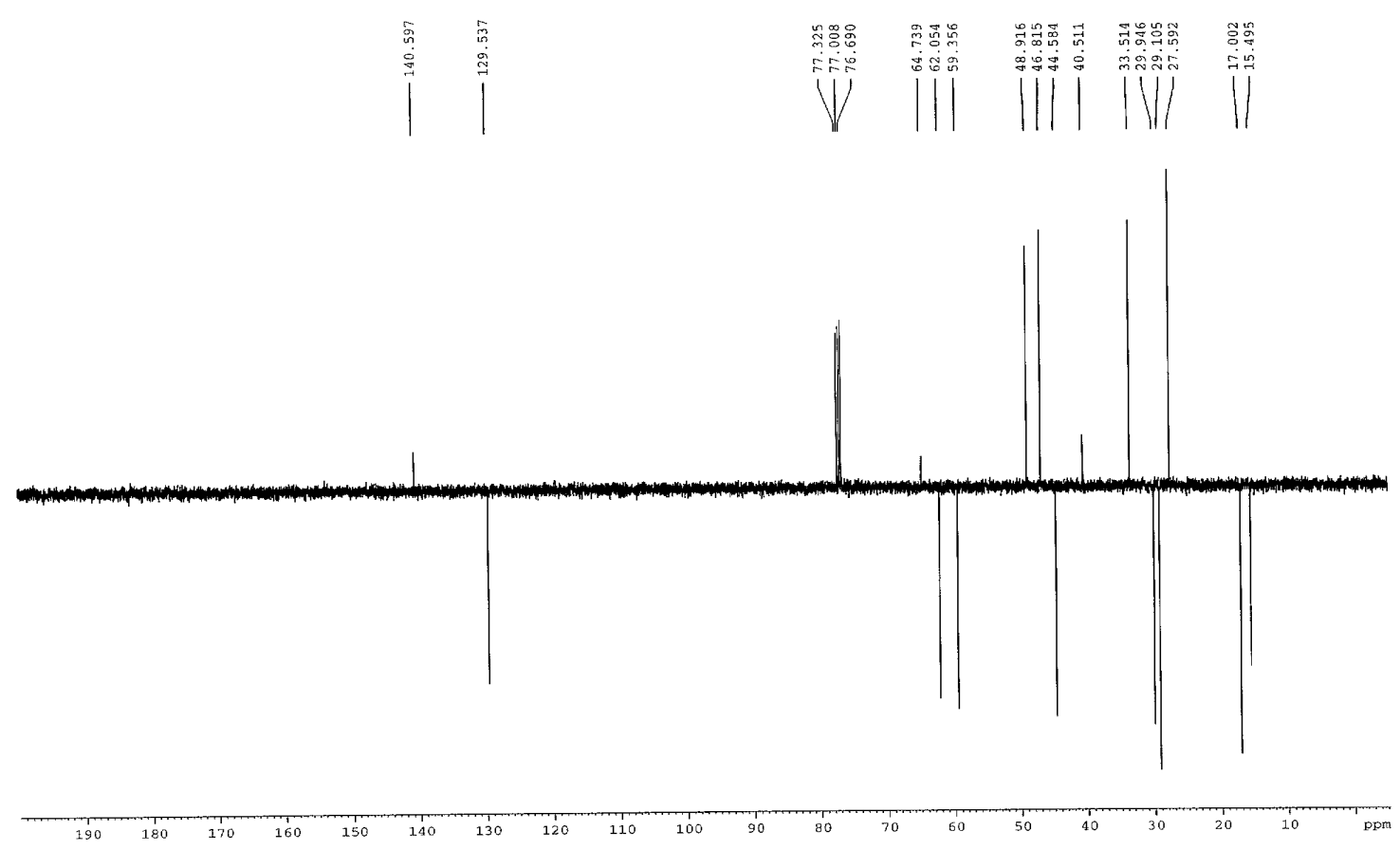

S-27 
${ }^{1} \mathrm{H}$ NMR spectrum of $14\left(400 \mathrm{MHz}, \mathrm{CDCl}_{3}\right)$

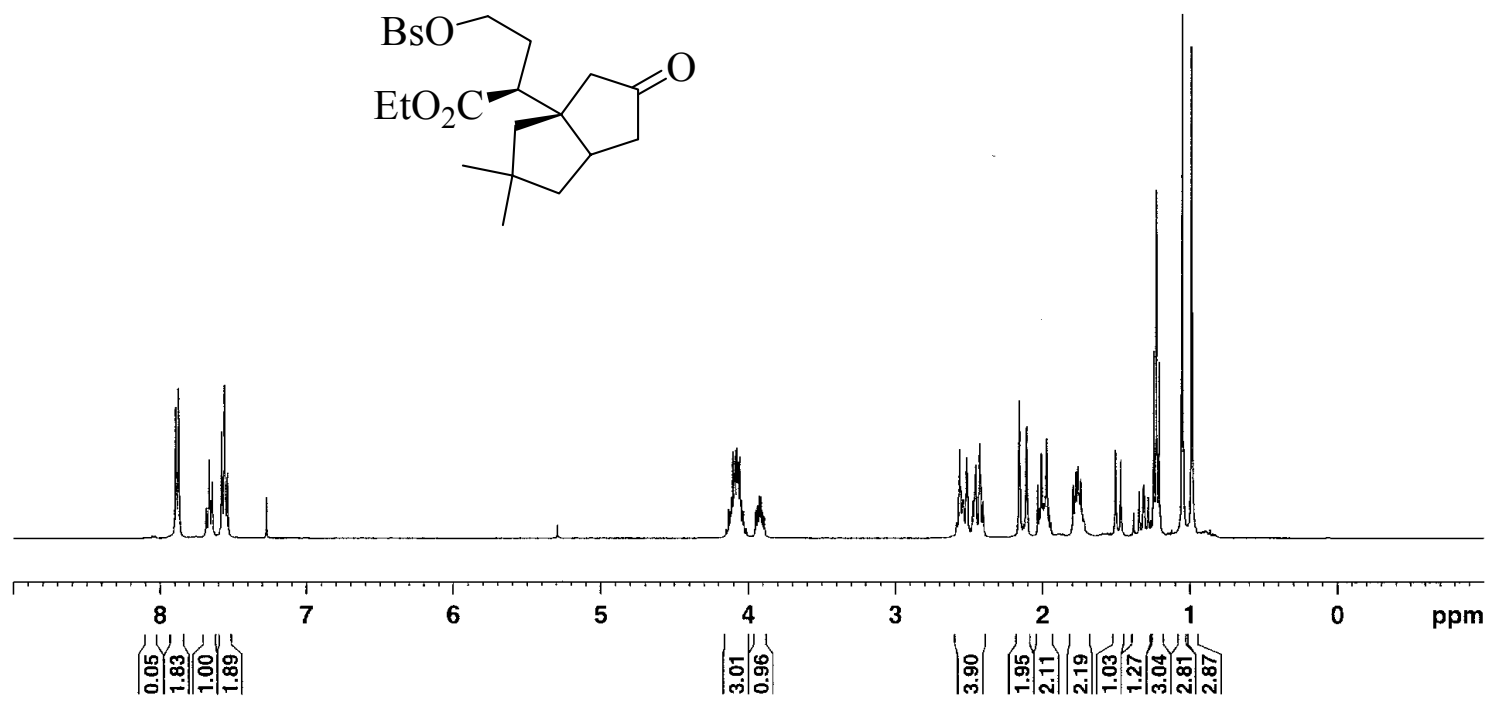

${ }^{13} \mathrm{C}$ APT NMR spectrum of $14\left(100 \mathrm{MHz}, \mathrm{CDCl}_{3}\right)$
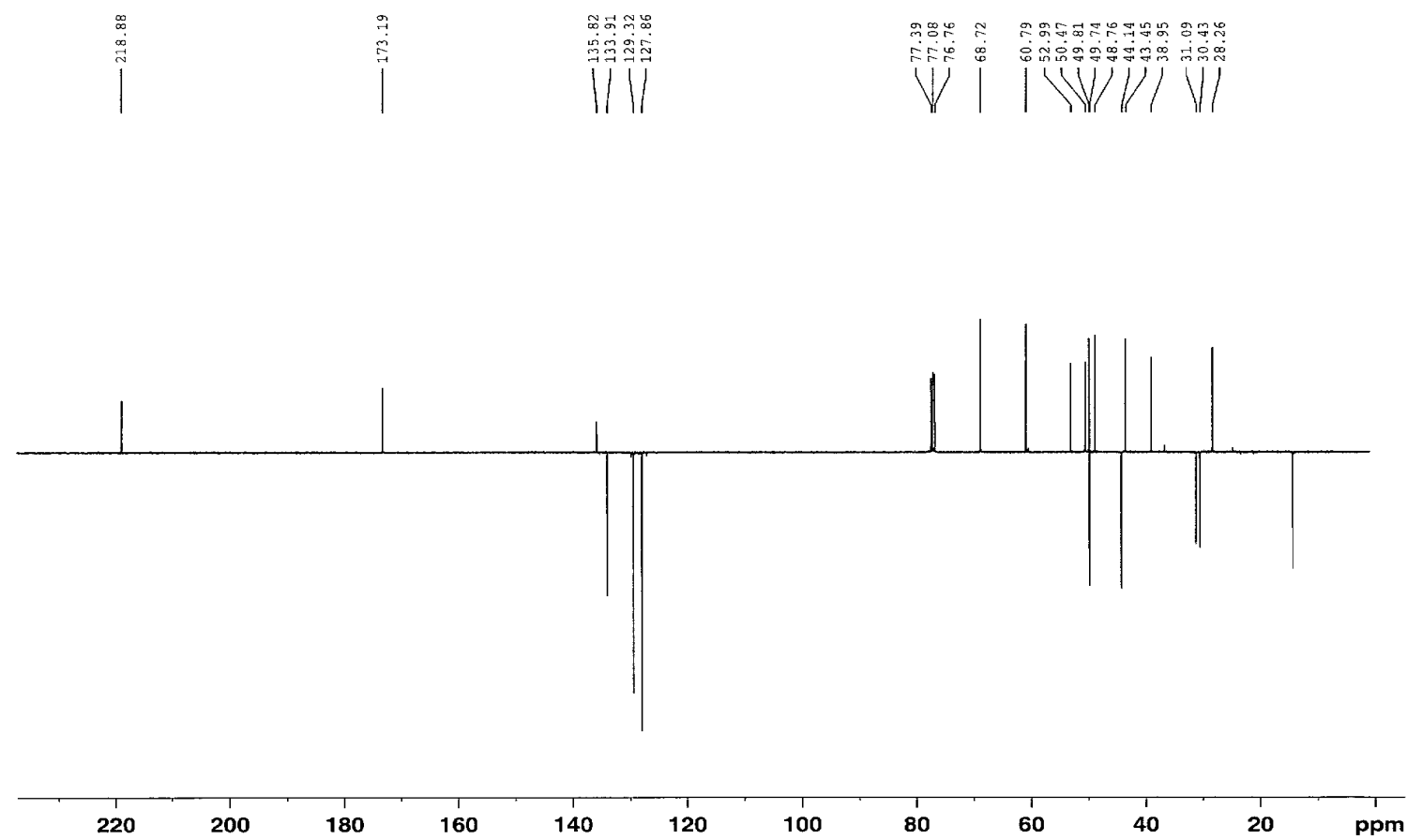
${ }^{1} \mathrm{H}$ NMR spectrum of $15\left(400 \mathrm{MHz}, \mathrm{CDCl}_{3}\right)$

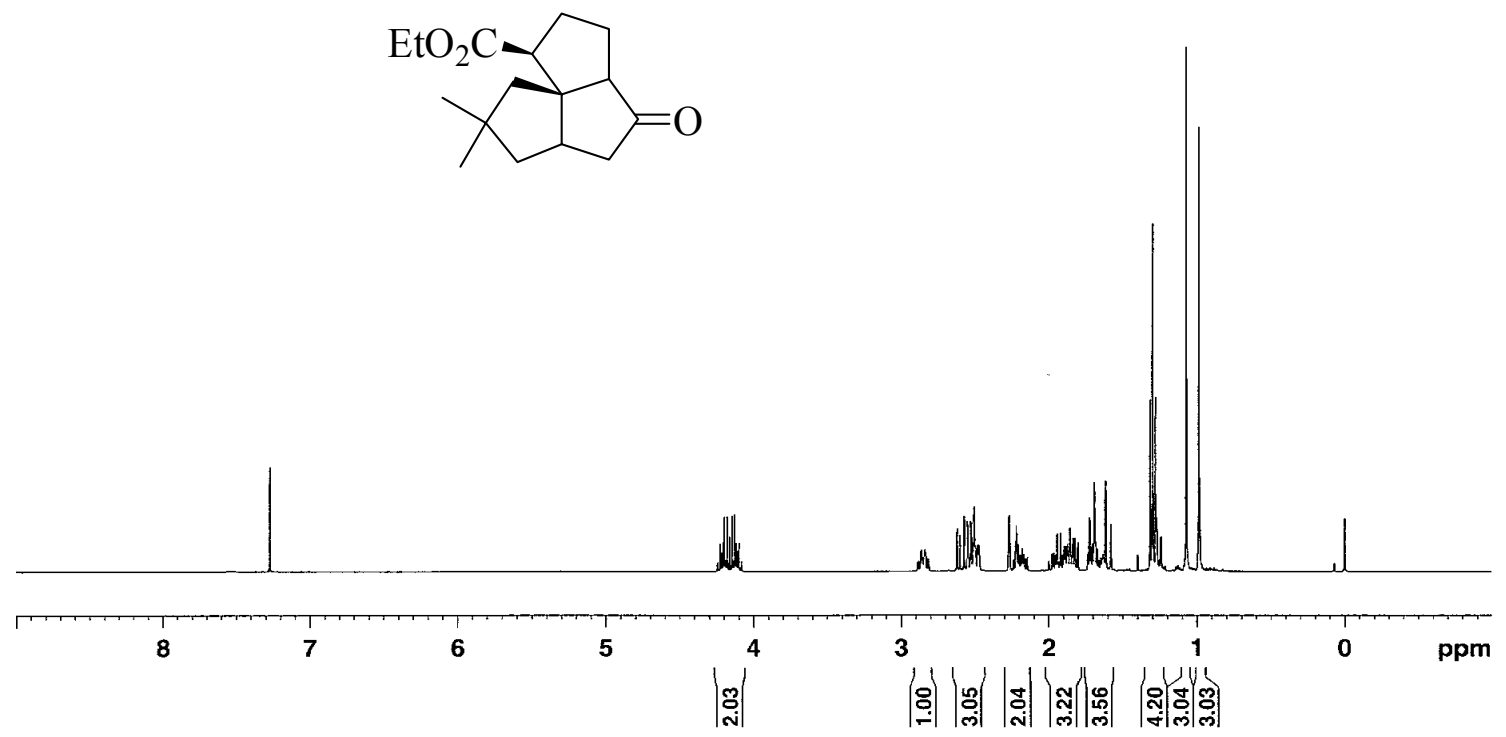

${ }^{13} \mathrm{C}$ APT NMR spectrum of $15\left(100 \mathrm{MHz}, \mathrm{CDCl}_{3}\right)$
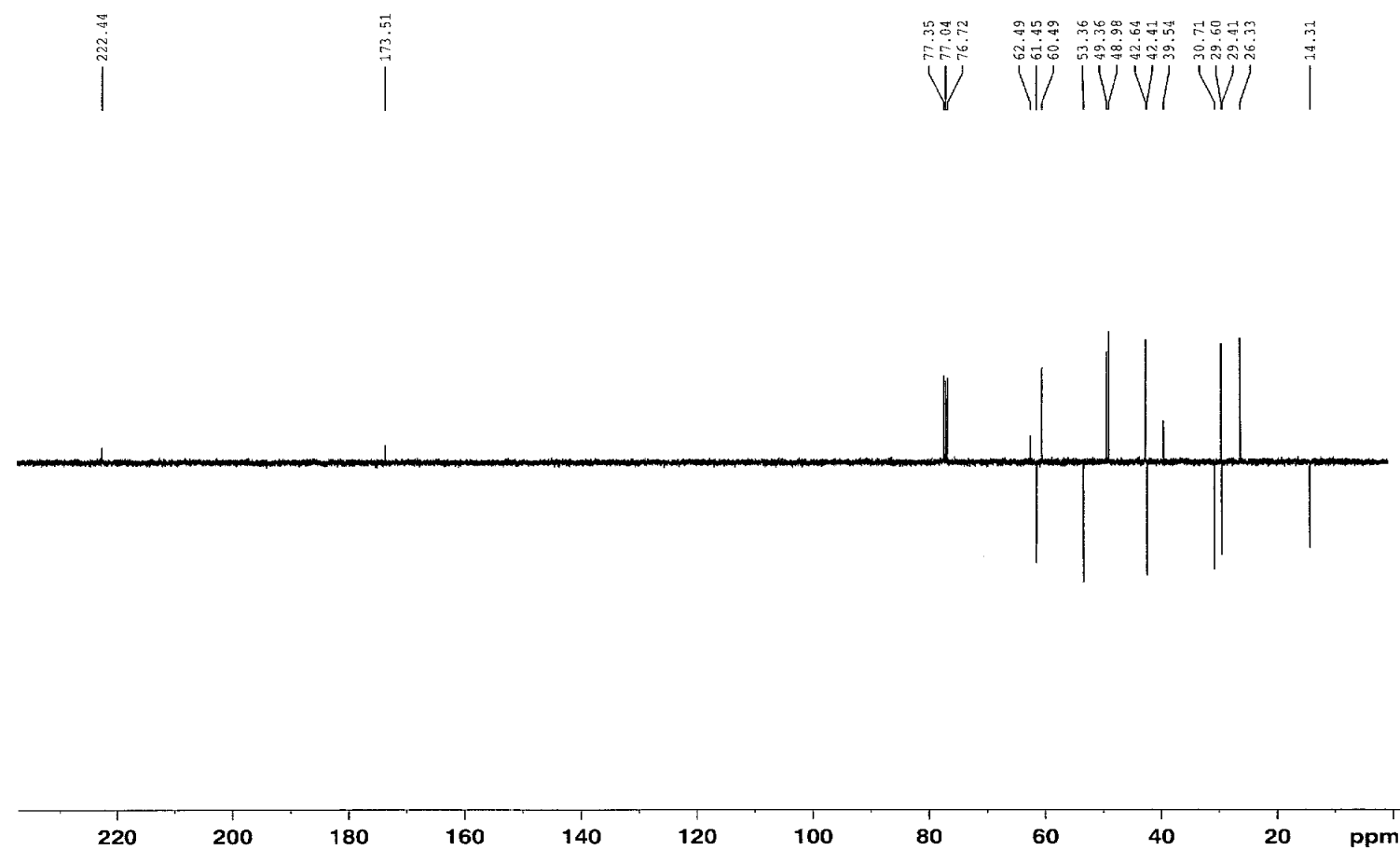

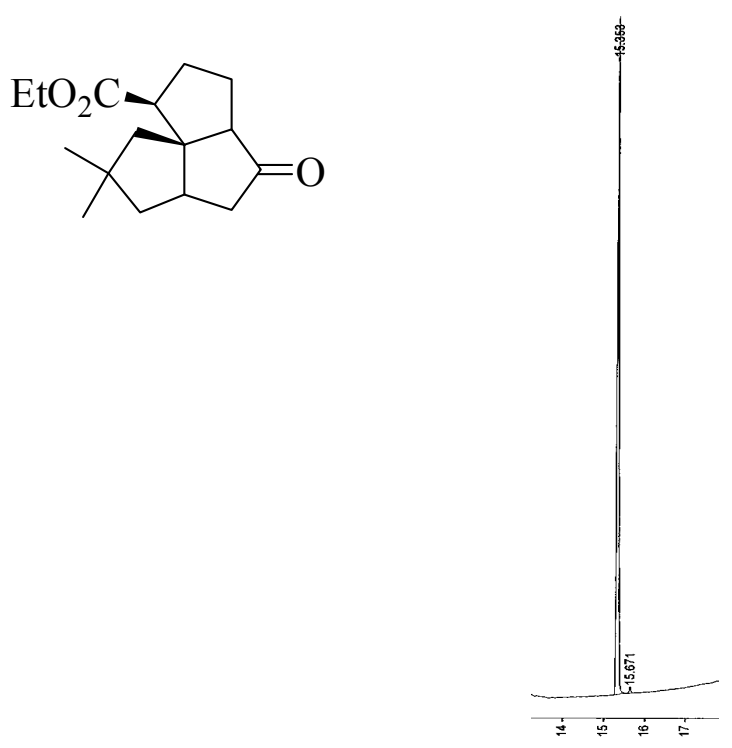

\begin{tabular}{|c|c|c|c|c|c|c|c|c|}
\hline & & & Ret. & Time & & & Width & \\
\hline $\begin{array}{c}\text { Peak } \\
\text { No. }\end{array}$ & Peak & Result & Time & offset & Height & Sep. & $1 / 2$ & Status \\
\hline---- & ----------- & -------- & ------- & ---n- & $-\ldots-\ldots---$ & --- & $-\ldots-$ & \\
\hline 1 & & 99.0449 & 15.353 & 0.000 & 14752 & BB & 2.9 & \\
\hline 2 & & 0.9551 & 15.671 & 0.000 & 142 & BB & 3.0 & \\
\hline -- & ------- & 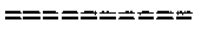 & $---\infty--$ & $=$ & $== \pm=======$ & --- & ---- & \\
\hline & Totals: & 100.0000 & & 0.000 & 14894 & & & \\
\hline
\end{tabular}


${ }^{1} \mathrm{H}$ NMR spectrum of $17\left(400 \mathrm{MHz}, \mathrm{CDCl}_{3}\right)$

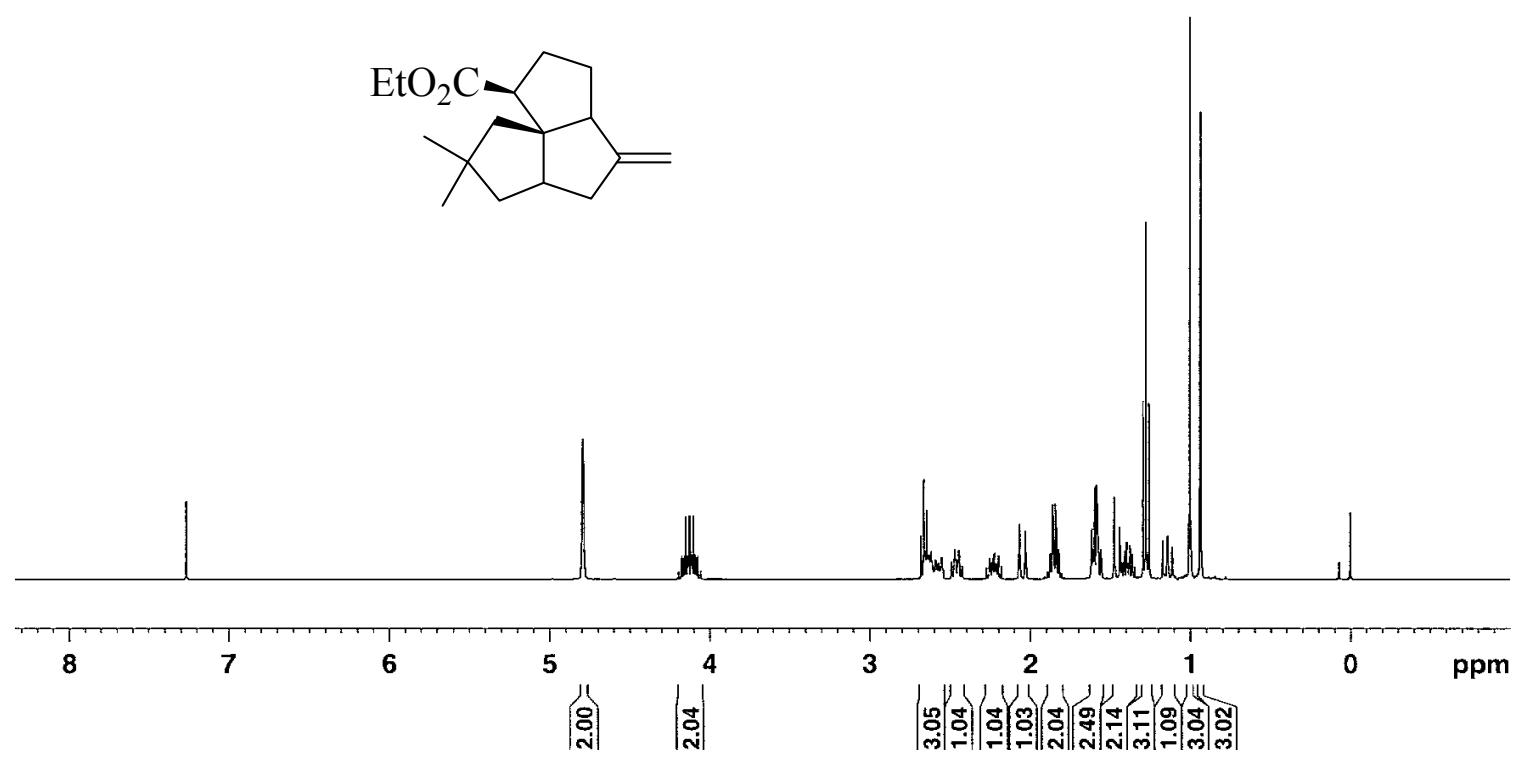

${ }^{13} \mathrm{C}$ APT NMR spectrum of $17\left(100 \mathrm{MHz}, \mathrm{CDCl}_{3}\right)$
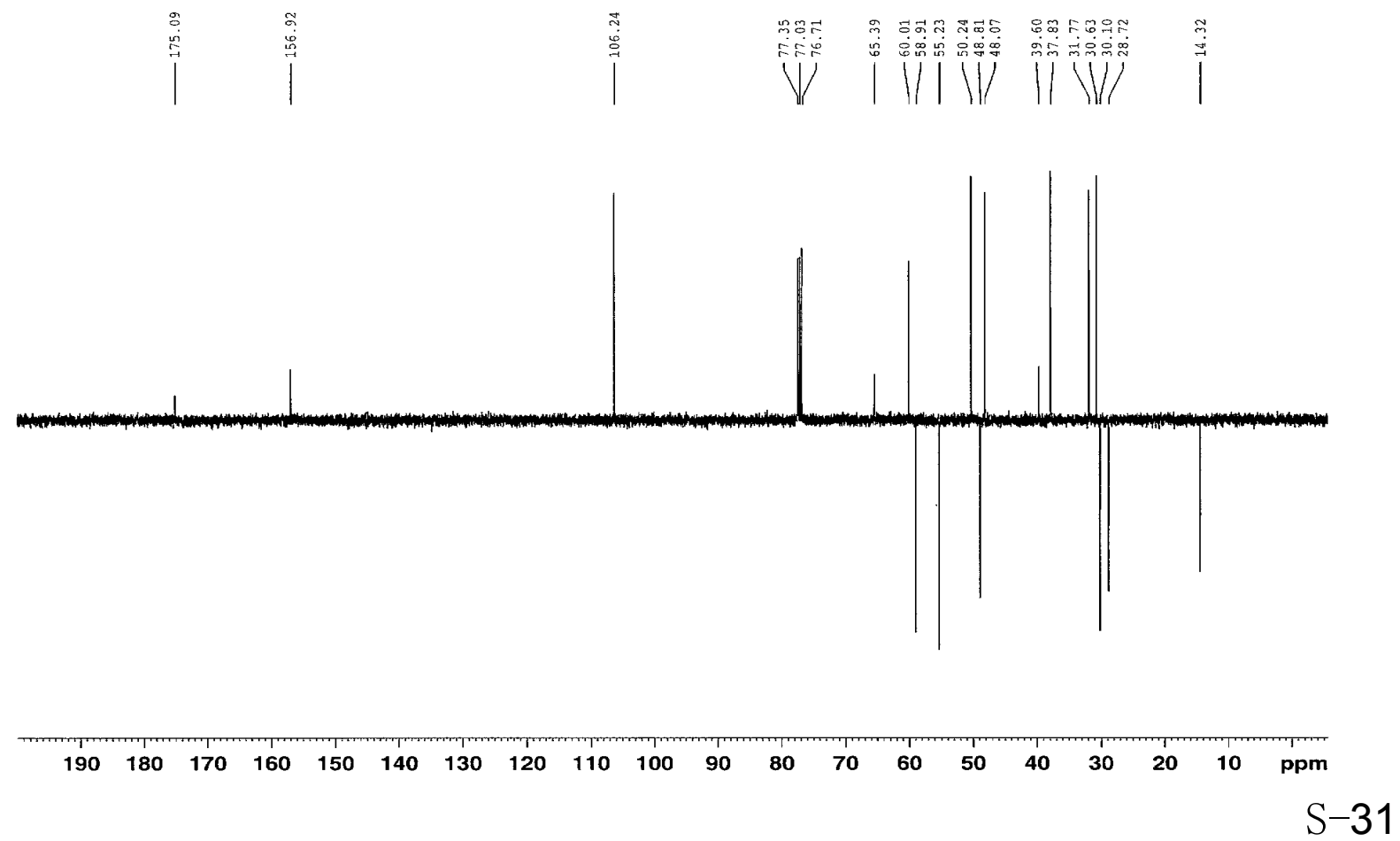

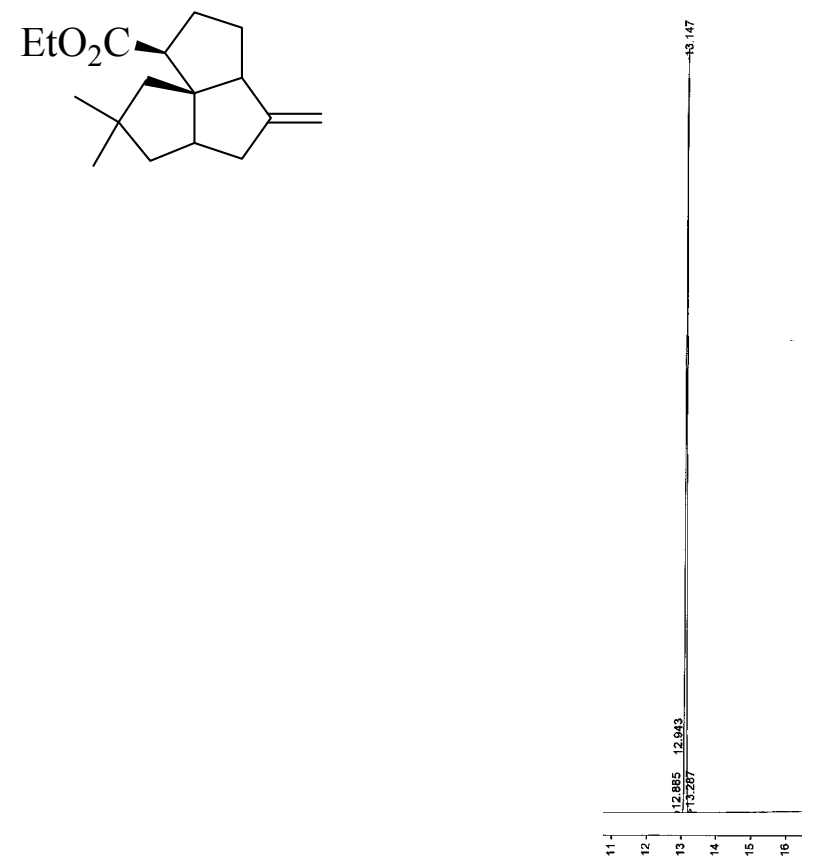

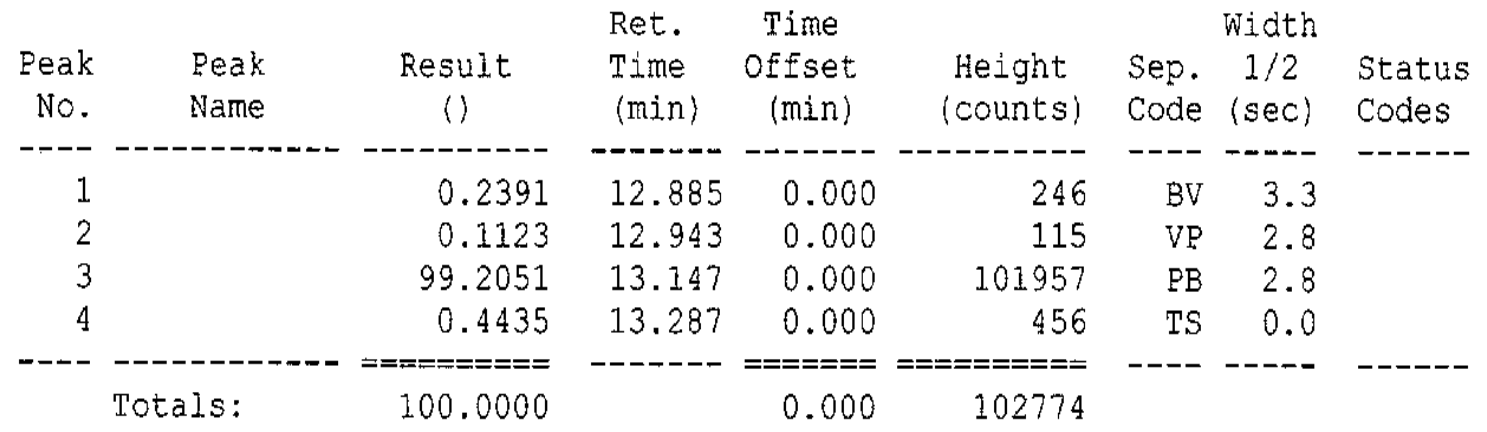

